\title{
Article \\ Effect of Horizontal Multidirectional Cyclic Loading on Piles in Sand: A Numerical Analysis
}

\author{
Orianne Jenck*(D), Armita Obaei, Fabrice Emeriault and Christophe Dano \\ Grenoble Alpes University, CNRS, Grenoble INP, 3SR, 38000 Grenoble, France; armita.obaei@gmail.com (A.O.); \\ fabrice.emeriault@3sr-grenoble.fr (F.E.); christophe.dano@3sr-grenoble.fr (C.D.) \\ * Correspondence: orianne.jenck@3sr-grenoble.fr
}

check for updates

Citation: Jenck, O.; Obaei, A.; Emeriault, F.; Dano, C. Effect of Horizontal Multidirectional Cyclic Loading on Piles in Sand: A Numerical Analysis. J. Mar. Sci. Eng. 2021, 9, 235. https://doi.org/ $10.3390 /$ jmse9020235

Academic Editor: Luke J. Prendergast

Received: 26 January 2021

Accepted: 18 February 2021

Published: 23 February 2021

Publisher's Note: MDPI stays neutral with regard to jurisdictional claims in published maps and institutional affiliations.

Copyright: (c) 2021 by the authors. Licensee MDPI, Basel, Switzerland. This article is an open access article distributed under the terms and conditions of the Creative Commons Attribution (CC BY) license (https:// creativecommons.org/licenses/by/ $4.0 /)$.

\begin{abstract}
Foundations of offshore and nearshore wind energy production systems are subjected to multidirectional and cyclic loads, due to the combined action of wind and waves and in the particular case of mutualized anchor foundations for floating wind turbines, to the phase shift between the loads generated in the adjacent anchored turbines. This article presents a three-dimensional numerical model developed with FLAC3D to analyse the impact of the change in direction of the horizontal load during the cycles. The typical case of a $1.7 \mathrm{~m}$ diameter and $10 \mathrm{~m}$-long pile founded in a dense homogeneous sand is considered. A specific procedure has been implemented to apply forcecontrolled cycles with a change in lateral load direction. The results are compared to mono-directional lateral cyclic loads with the same average and cyclic forces. The results of the parametric study highlight the effect of the average value and amplitude of the cyclic loading on the accumulation of pile head horizontal displacements during the cycles. When a multidirectional cyclic loading is applied, it also leads to an accumulation of the deviated horizontal displacements, and the resulting accumulated horizontal displacements are larger than for a mono-directional cyclic loading of the same amplitude.
\end{abstract}

Keywords: numerical modelling; pile; lateral cyclic loading; multidirectional loading; offshore wind turbine

\section{Introduction}

Wind power offers an interesting source of energy, leading to the current development of onshore, nearshore and offshore wind farms. Compared to onshore, nearshore and offshore wind turbines benefit from a number of advantages such as limited visual impact, higher and more constant wind speed, and the possibility of using large capacity turbines, resulting in higher power generation. There are several foundation concepts for offshore wind turbines, which specifically depend on the loading, water depth and soil conditions: gravity-base; monopole, tripile, tripod, jacket or anchor for floating structures [1,2]. In the case of floating wind turbines, the structures are connected to the foundation system through several anchor lines and the cyclic load then acts in multiple directions, due to the combined action of wind and waves. In the particular case of mutualized anchor foundations for floating wind turbines, the foundations are also subjected to the phase shift between the loads generated in the adjacent anchored turbines. This study thus focuses on the case of piles as mutualized anchors for floating wind turbines, thus submitted to multidirectional lateral cyclic loads.

When a pile is subjected to lateral loads, one of the essential features is known to be the pile bending stiffness compared to the surrounding soil stiffness and strength. Short rigid piles are mainly submitted to displacement and rotation, whereas for flexible piles, the soil-pile behaviour is affected by the flexibility of the pile (Figure 1). 


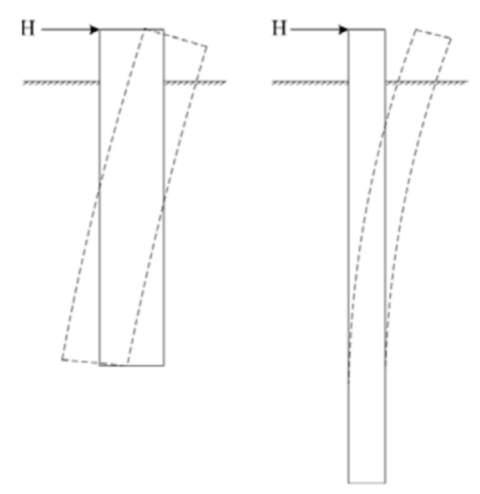

Figure 1. Rigid vs. flexible pile submitted to lateral load.

Poulos and Hull (1989) [3] defined the rigidity parameter R (Equation (1)), depending on the pile Young modulus $E_{p}$ and quadratic moment $I_{p}$, and on the soil "stiffness" $E_{s}$. They suggested that a pile with a length less than $1.48 \mathrm{R}$ behaves rigidly, and if the length exceeds $4.44 \mathrm{R}$, the pile behaves flexibly. However, one should note that the choice of a homogeneous soil stiffness $E_{s}$ is still problematic in practice:

$$
R=\left(\frac{E_{p} I_{p}}{E_{s}}\right)^{0.25}
$$

The piles under lateral load are traditionally designed using the $p-y$ curve concept $[4,5]$, which formulates the soil response as uncoupled non-linear springs (Winkler approach), relating the soil pressure $p$ acting against the pile shaft and the corresponding lateral displacement $y$ of the pile. However, the concept has been developed based on semiempirical relations for flexible piles under monotonic loading and has some limitations for large diameter piles, as particularly highlighted by numerical modelling approaches $[6,7]$. Indeed, when a pile behaves rigidly, a passive wedge of soil beneath the point of zero deflection will develop, an aspect which is not considered in the current methodology.

Furthermore, design methods of these offshore piles and their response to cyclic lateral loading are an important issue in the geotechnical engineering practice and has been addressed by several studies around the world, mainly focusing on mono-directional loading.

Among others, experimental testing studies in centrifuges have been reported in [8-10]. Most of the studies are synthetized in the SOLCYP Project recommendations [11]. All these studies have highlighted the lateral displacement accumulation during the cycles. Based on field-scale piles, Lin and Liao (1999) [12] proposed a logarithmic law as

$$
\mathrm{y}_{\mathrm{N}} / \mathrm{y}_{1}-1=\alpha \ln \mathrm{N} \quad(\mathrm{N} \geq 1)
$$

where $\mathrm{y}_{1}$ and $\mathrm{y}_{\mathrm{N}}$ are the pile head lateral displacement at first loading and at Nth cycle, respectively, and $\alpha$ is a parameter which thus represents the displacement accumulation due to the cycles. This parameter $\alpha$ highly depends on the loading type, cyclic amplitude, pile installation, soil properties, pile embedment length and pile-soil relative stiffness. For instance, Verdure et al. (2003) [13] presented a linear relationship of $\alpha$ value with the cyclic amplitude, based on the centrifuge tests of a flexible pile in a dry dense sand under one-way cyclic loading. They proposed $\alpha=0.18 \Delta \mathrm{H} / \mathrm{H}_{\max }$ where $\Delta \mathrm{H}$ is the cyclic amplitude and $\mathrm{H}_{\max }$ is the maximum loading. They also mentioned that the load cycles have much more effect on the pile displacement when the maximum applied load is closer to the ultimate lateral static resistance of the pile. Concerning the effect of pile-soil relative stiffness, the effect of cycles is more important for flexible piles than for rigid piles [14]. For rigid piles, the value of $E_{p} I_{p}$ has no more influence [11].

Based on the expression proposed by Rosquoët et al. (2007) [15] obtained from experimental results on flexible piles in sand, the SOLCYP recommendations [11] propose 
the following logarithmic law for the case of intermediate or rigid piles in sand, thus also accounting for the pile bending stiffness:

$$
\begin{gathered}
\mathrm{y}_{\mathrm{N}} / \mathrm{y}_{1}-1=0.102 / \mathrm{CR} \times \ln (\mathrm{N}) \times\left(\mathrm{H}_{\mathrm{c}} / \mathrm{H}_{\max }\right)^{0.35} \\
\mathrm{~N} \geq 1
\end{gathered}
$$

where $C R$ is a rigidity coefficient defined as

$$
\mathrm{CR}=\left[\mathrm{E}_{\mathrm{p}} \mathrm{I}_{\mathrm{p}} /\left(\mathrm{E}_{\mathrm{p}} \mathrm{I}_{\mathrm{p}}\right)_{\mathrm{fl}}\right]^{1 / 5}
$$

$\left(E_{p} I_{p}\right)_{f l}$ corresponds to the limit value of the pile bending stiffness $E_{p} I_{p}$ for flexible piles and should be first assessed by analysing the effect of the pile bending stiffness on the pile head displacement under monotonic horizontal loading. $\left(\mathrm{E}_{\mathrm{p}} \mathrm{I}_{\mathrm{p}}\right)_{\mathrm{fl}}$ corresponds to the value below which the bending stiffness has a large impact on the pile head displacement. For flexible piles, $\mathrm{CR}=1 . \mathrm{H}_{\max }$ and $\mathrm{H}_{\mathrm{c}}$ are, respectively, the maximum lateral load and half of the amplitude of the cyclic loading (see Equations (5) and (6)).

An alternative or additional approach to experimental and semi-empirical investigation consists of implementing numerical models. In this approach, special attention should be paid to the modelling of the soil (and pile-soil interface), by using relevant constitutive models, even under monotonic loading [16]. A few numerical approaches under lateral cyclic loading have been proposed. For instance, Achmus et al. (2009) [17] implemented an approach termed "degradation stiffness model" to account for long-term cyclic lateral loading of piles. Model parameters were assessed from cyclic triaxial tests results with up to $10^{4}$ cycles, and numerical results were compared to test results of pile in sand, showing a good agreement. The numerical parametric study thus permitted to develop design charts.

Nevertheless, most of these studies under lateral cyclic loading focus on the case of mono-directional loading. The behaviour of the piles under lateral loading that varies in direction and amplitude has been little studied to date, and even less under cyclic loading conditions. Su and $\mathrm{Li}$ (2013) [18] investigated the effect of multidirectional lateral loading using a finite-element modelling approach, by applying an imposed trajectory at pile head (with no unloading). They obtained that the lateral resistance of the pile is lower under multidirectional than under mono-directional loading. In this latter, the directions of the force increment vector and lateral displacement increment vectors are generally non-coaxial. Lovera et al. (2020) [19] extended the framework of $p-y$ curve method to multidirectional loading, and they obtained a misalignment between load direction and total displacement when the loading direction changes.

Concerning the effect of multidirectional lateral loading under cyclic conditions, a few experimental studies were conducted. Mayoral et al. (2016) [20] focused on the case of a pile in soft clay under seismic loading using an experimental modelling approach. They highlighted the influence of the cyclic loading path on the pile response and they noted that the concept of $p-y$ curve could not simply be applied in two orthogonal directions. Rudolph et al. (2014) [21] performed centrifuge experiments of a large-diameter pile in sand, with up to 13,000 cycles and a variation of loading direction of $0^{\circ}, 30^{\circ}, 60^{\circ}$ or $90^{\circ}$. They highlighted the significant increase in lateral displacement accumulation, even under load levels representative of serviceability conditions, which makes the current guidelines-as in the American Petroleum Institute (API) recommendations [4]—non-conservative.

Experimental studies are complex to perform, expensive and time consuming, even more under complex loading paths, with cycles and loading direction changes, so that complete parametric studies under such complex and multiple conditions are difficult to conduct. Numerical studies thus can help understanding the behaviour under complex conditions and highlight governing features. Moreover, numerical studies allow accessing information difficult to obtain experimentally, such as the bending moment in the pile. However, no numerical study of pile subjected to lateral multidirectional cyclic loading has been reported in the literature to date. 
The objective of this work was to develop a numerical approach to acquire knowledge concerning the system behaviour and governing parameters, in the case of multi-directional and cyclic lateral loading as encountered for mutualized anchoring piles. The aim was to be able to estimate the accumulated pile displacements, in particular at the mudline, and the accumulated pile rotation and/or bending, in such complex loading situations.

To achieve these objectives, a conceptual 3D numerical model using the commercial finite difference software Flac3D [22] was developed, simulating the pile, the surrounding ground mass and their interface. Specific loading procedures are implemented to apply mono-directional and then multi-directional cyclic loadings. The multi-directional loading consists of varying the direction of the lateral load during the unloading-reloading process.

\section{Materials and Methods for the Numerical Modelling}

\subsection{Model Specifications}

In the case of mutualized anchor piles for floating wind turbines, each pile was connected to several turbines (Figure 2) and each turbine was connected to several piles. In the case depicted in Figure 2, the horizontal load applied to a pile head $(\mathrm{H})$ thus results from the tension applied by both lines $\left(\mathrm{H}_{1}\right.$ and $\left.\mathrm{H}_{2}\right) . \mathrm{H}_{1}$ and $\mathrm{H}_{2}$ both vary in time, more or less independently from the other, thus resulting in a multidirectional cyclic vertical (not investigated here) and horizontal loading: $\mathrm{H}=\mathrm{f}(\omega, \mathrm{t})$, where $\omega$ is the loading direction (or azimuth) and $t$, time.

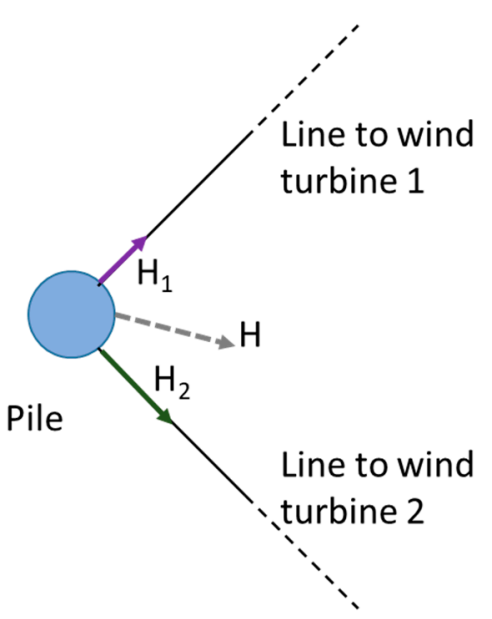

Figure 2. Concept of mutualized pile foundations for floating wind turbines (conceptual orientations).

The reference case considered in this study is taken from a relevant case proposed by France Energies Marines [23], in order to proceed with the development of the numerical model. Figure 3a depicts this relevant case in terms of the horizontal loading on an anchored pile (named A1), induced by two anchored lines (M1-L4 and M2-L1) connected to two floating turbines (M1 and M2). In this case, the resulting horizontal force $(\mathrm{H})$ at pile head varies between $\mathrm{H}_{\max }=1.77 \mathrm{MN}$ down to $\mathrm{H}_{\min }=1.25 \mathrm{MN}$, with a change of force direction of $30^{\circ}$ in a horizontal plane (azimuth change). Figure $3 \mathrm{~b}$ depicts the considered loading path $\mathrm{H}$ as a function of the azimuth $\omega$ adopted in the numerical study. In this exploratory study, unloading and reloading follow the same path. The case of the monodirectional loading of the same loading amplitude ( $\mathrm{H}$ between 1.25 and $1.77 \mathrm{MN}$, thus with $\omega=$ constant, equal to $0^{\circ}$ on Figure $3 \mathrm{~b}$ ) is first considered in order to (i) proceed to a numerical model validation under a more "conventional" situation; (ii) highlight the impact of loading azimuth change on the pile response afterwards. 

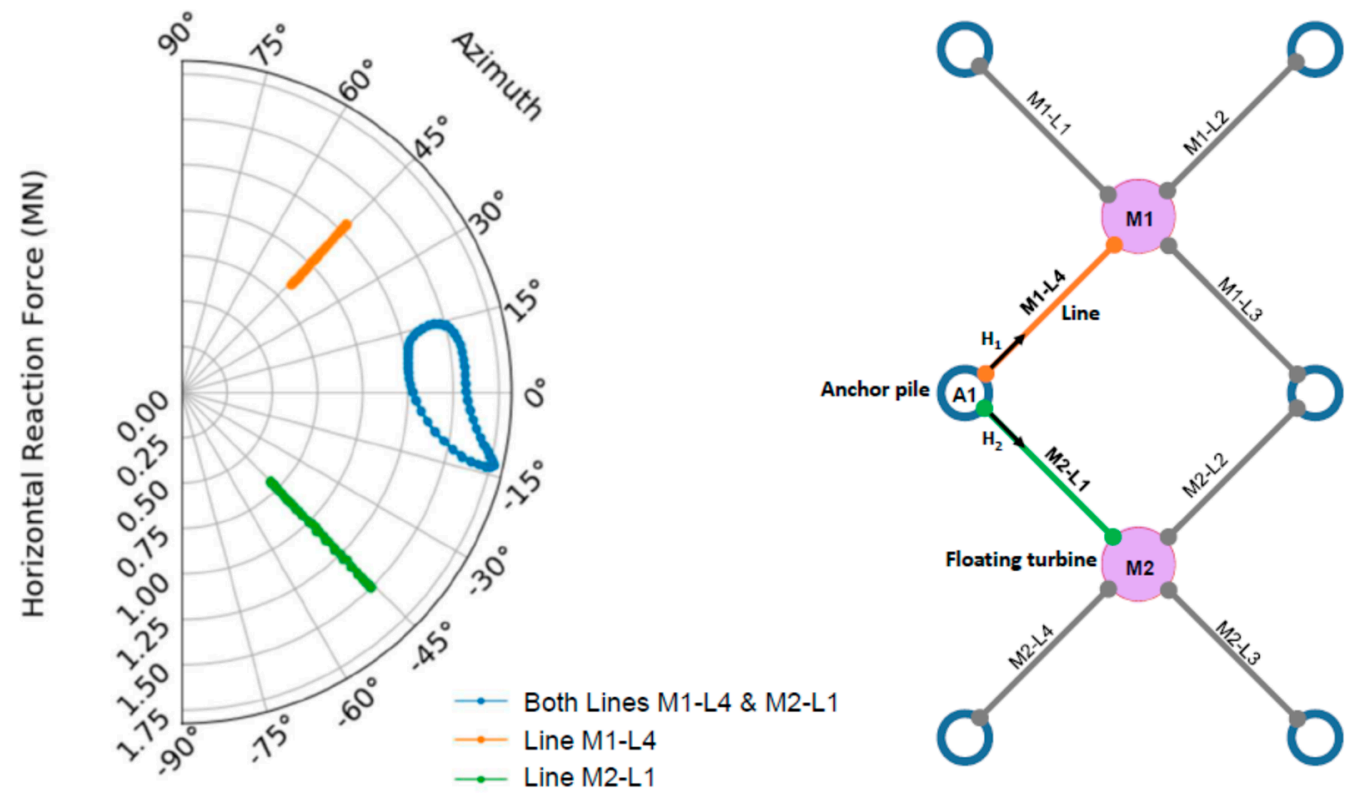

(a)
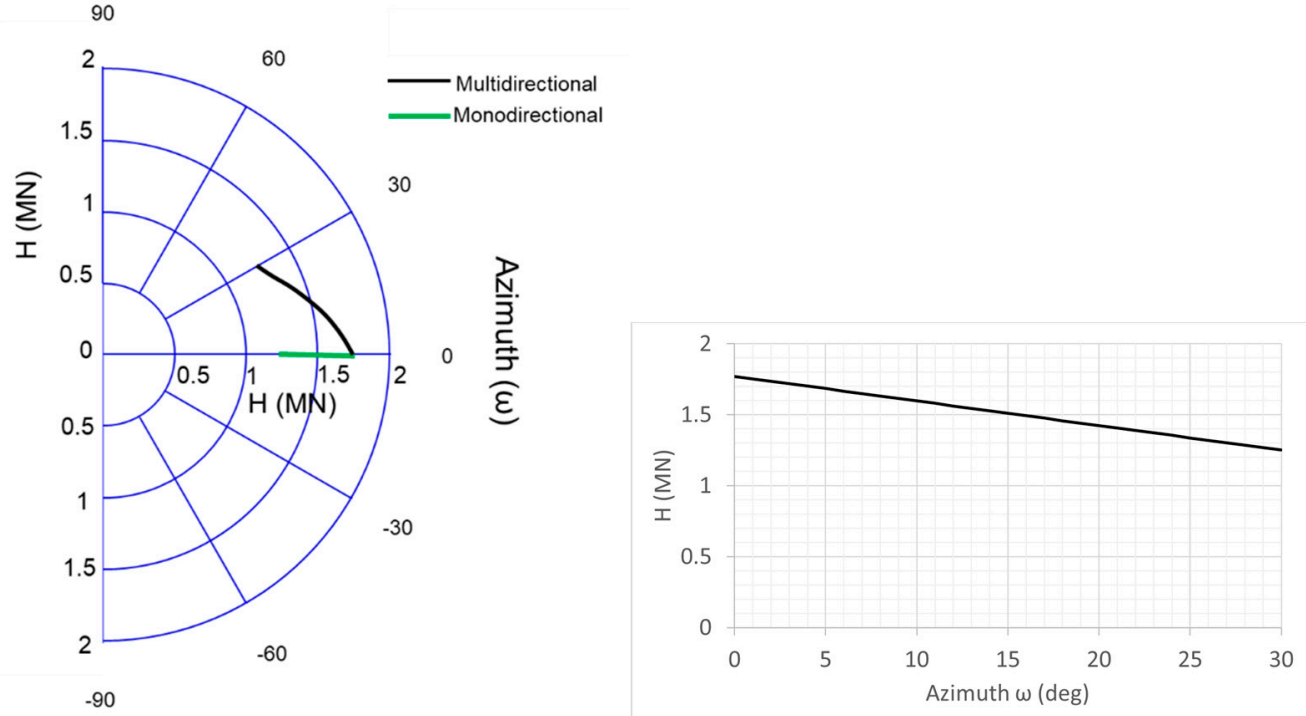

(b)

Figure 3. Multidirectional horizontal loading path applied on a pile head. (a) Relevant loading case applied on pile anchor A1 by 2 anchor lines M2-L1 and M1-L4, adapted from [23]. (b) Reference case of the loading path for the current numerical study.

As an initial numerical parametric study, the impact of the average horizontal force and amplitude of mono-directional cycling loading (i.e., $\omega=0^{\circ}$ ) is investigated beforehand.

The average lateral load $H_{m}$ and half-amplitude of cyclic loading $H_{c}$ are defined as

$$
\begin{aligned}
& H_{m}=\frac{H_{\max }+H_{\min }}{2} \\
& H_{c}=\frac{H_{\max }-H_{\min }}{2}
\end{aligned}
$$

The reference case corresponds thereby to $H_{m}=1.51 \mathrm{MN}$ and $H_{c}=0.26 \mathrm{MN}$. The $H_{c} / H_{\max }$ ratio (cf. Equation (3)) is equal to 0.147. Additionally, the ultimate lateral loading 
for the case study is numerically determined to equal $H_{\text {lim }}=4.3 \mathrm{MN}$ (see Section 3.1) in order to compute the average force ratio $\left(H_{m} / H_{\text {lim }}\right)$ and cyclic amplitude ratio $\left(H_{c} / H_{\text {lim }}\right)$.

The numerical parametric study conducted is summarized in Table 1 and Figure 4. The reference case is "case 1". Cases with a larger cyclic amplitude than the reference case were mainly investigated (cases 3-7), whereas case 2 is for a smaller amplitude. The effect of the average force value for a fixed amplitude can be explored by comparing cases 3,4 and 5, and cases 6 and 7. Figure 4 also highlights that only "one-way" cycles are applied (no load reversal).

Table 1. Parametric study under mono-directional cyclic loading.

\begin{tabular}{cccccccc}
\hline Case & $\mathbf{H}_{\max }(\mathbf{M N})$ & $\mathbf{H}_{\min } \mathbf{( M N )}$ & $\mathbf{H}_{\mathbf{m}} \mathbf{( M N )}$ & $\begin{array}{c}\text { Avg. Force Ratio } \\
\mathbf{H}_{\mathbf{m}} / \mathbf{H}_{\mathbf{l i m}}\end{array}$ & $\mathbf{H}_{\mathbf{c}} \mathbf{( M N )}$ & $\begin{array}{c}\text { Cyclic Amplitude } \\
\text { Ratio } \mathbf{H}_{\mathbf{c}} / \mathbf{H}_{\mathbf{l i m}}\end{array}$ & $\mathbf{H}_{\mathbf{c}} / \mathbf{H}_{\mathbf{m a x}}$ \\
\hline 1 & 1.77 & 1.25 & 1.51 & 0.35 & 0.26 & 0.06 & 0.147 \\
2 & 1.77 & 1.50 & 1.64 & 0.38 & 0.14 & 0.03 & 0.08 \\
3 & 1.77 & 1.00 & 1.39 & 0.32 & 0.39 & 0.09 & 0.220 \\
4 & 2.02 & 1.25 & 1.64 & 0.38 & 0.39 & 0.09 & 0.172 \\
5 & 2.27 & 1.50 & 1.89 & 0.44 & 0.39 & 0.13 & 0.322 \\
6 & 1.77 & 0.64 & 1.21 & 0.28 & 0.57 & 0.13 & 0.222 \\
7 & 2.57 & 1.44 & 2.01 & 0.47 & 0.57 & & 0.13 \\
\hline
\end{tabular}

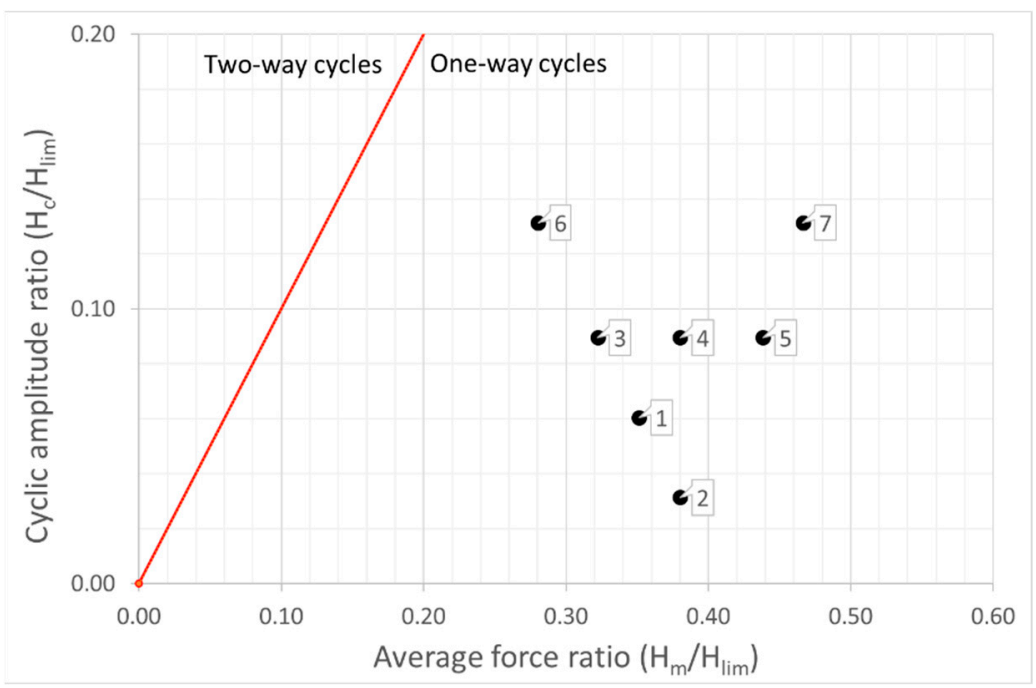

Figure 4. Parametric study under mono-directional cyclic loading: cases 1-7.

The period of loading cycles is around $10 \mathrm{~s}$. In the numerical model, no dynamic effect is thus considered-i.e., cyclic loading is applied under quasi-static conditions, and calculation will be performed under drained conditions, all the more that a sand stratum is envisaged.

The case of $1.7 \mathrm{~m}$-diameter $(\mathrm{D}=1.7 \mathrm{~m})$ and $10 \mathrm{~m}$-long pile $(\mathrm{L}=10 \mathrm{~m})$ founded in a dense homogeneous sand mass was examined. The pile is a hollow pile made of steel, with a wall thickness of $35 \mathrm{~mm}$ (internal diameter $\mathrm{D}_{\text {int }}=1.63 \mathrm{~m}$ ). With $E_{p}=200 \mathrm{GPa}$ and a pile quadratic moment $I_{p}=\pi / 64 \times\left(\mathrm{D}^{4}-\mathrm{D}_{\text {int }}{ }^{4}\right)=0.0635 \mathrm{~m}^{4}$, the flexural pile rigidity is $E_{p} \times I_{p}=1.27 \times 10^{10} \mathrm{~N} \cdot \mathrm{m}^{2}$. The soil "stiffness" $\mathrm{E}_{s}$ is taken equal to $50 \mathrm{MPa}$. The value of $R$ of Equation (1) is then $R=4.0$ and the pile length is $L=10 \mathrm{~m}=2.5 \mathrm{R}$. The pile length being between 1.48 and $4.44 \mathrm{R}$, this pile is therefore supposed to have a medium relative flexibility [3].

Concerning the soil mass, a dense and homogenous layer of sand is considered. The main geotechnical characteristics that will be considered to calibrate the soil constitutive model for the numerical analysis are its submerged unit weight $\gamma^{\prime}=10.2 \mathrm{kN} / \mathrm{m}^{3}$; the 
maximum friction angle $\varphi=37^{\circ}$; the cohesion $\mathrm{c}=0 \mathrm{kPa}$; the dilation angle $\Psi=\varphi-30=7$; and a deformation modulus $\mathrm{E}_{\mathrm{S}}=50 \mathrm{MPa}$.

\subsection{Numerical Model}

The issue addressed in this study is a typical soil-structure interaction problem. It is handled here by implementing a numerical method termed a "direct method", since the soil mass and the structure elements are part of the same model, here in a continuum. The numerical model is developed with the commercial finite difference program FLAC3D (Fast Lagrangian Analysis of Continua) v. 5.01 [22]. The code uses an explicit numerical scheme that solves the dynamic equations of motion, even for static problems, in conjunction with an incremental constitutive law over a small time step, at discrete points in space (grid-points). This method is particularly well adapted for analysing the nonlinear behaviour of soils and soil-structure interactions. Because no matrices are formed, large three-dimensional calculations can be made without excessive memory requirements. Moreover, the internal programming language (FISH) and command-driven mode permit applying the desired loading path. This is a powerful feature when dealing with a complex multidirectional loading process, are addressed in this study.

The numerical model in a continuum consists of a soil mass with boundary conditions in which a pile made of zone elements is embedded (Figure 5). For the case of monodirectional horizontal loading of the pile, only half of the soil mass needs to be simulated due to symmetry condition (loading $\mathrm{H}$ is only applied in the $\mathrm{x}$ direction defined in Figure 5) and in order to optimize the calculation duration. On the contrary, the multi-directional loading case requires the implementation of a full model. The boundary conditions consist of node fixity in the $x$ direction for the vertical planes perpendicular to the $x$ direction, in the $y$ direction for the vertical planes perpendicular to the $y$ direction (also valid for the symmetry plane in the case of the half model) and in all directions for the horizontal bottom plane. The global size of the model and the size of the zones (mesh refinement) were the subject of a preliminary parametric study performed by Obaei (2020) [24]. The optimized models are depicted on Figure 5. The mesh is finer near the pile, and the size of the zones regularly increases when radially moving away from the pile axis. The model width is equal to $30 \mathrm{D}$, which was sufficient to prevent any boundary effect under pile lateral loading. The model for mono-directional loading (half model) contains 11,472 zones (10,464 for the soil and 1008 for the pile) and 12,956 grid-points; the model for multi-directional loading (full model) contains 22,944 zones (20,928 for the soil and 2016 for the pile) and 24,847 grid-points. The total height of the model could be optimized as only horizontal loading is applied on the pile head, and it is here equal to $17.85 \mathrm{~m}$, i.e., $7.85 \mathrm{~m}$ below the $10 \mathrm{~m}$ pile toe.
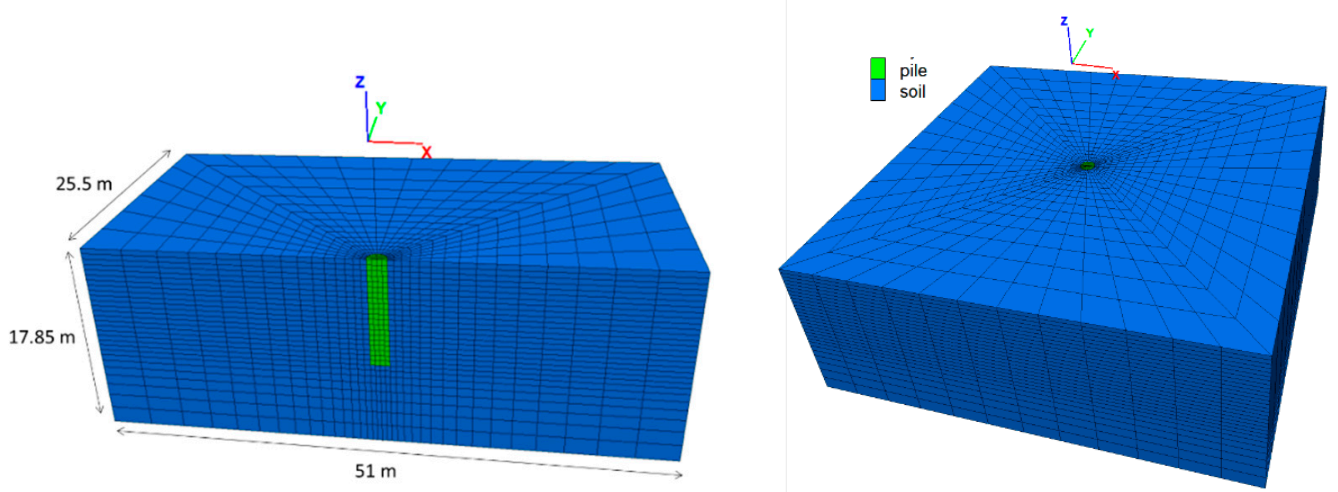

Figure 5. Numerical models for the mono-directional lateral loading (left) and multi-directional lateral loading (right). 
The pile is actually a hollow cylinder but in the present study it is simulated as a solid cylinder with an equivalent bending stiffness $\left(\mathrm{E}_{\mathrm{p}} \times \mathrm{I}_{\mathrm{p}}\right)$, for modelling simplification reasons. The pile is made of cylindrical zone elements. The quadratic moment for a solid cylinder of diameter $\mathrm{D}$ being $\mathrm{I}_{\mathrm{p}_{-} \mathrm{eq}}=\pi / 64 \times \mathrm{D}^{4}$, the equivalent Young modulus for the solid pile, is equal to $\mathrm{E}_{\mathrm{p} \_ \text {eq }}=31 \mathrm{GPa}$. The $10 \mathrm{~m}$-long pile is made of 20 slices of vertical zones plus an additional $0.1 \mathrm{~m}$-thick element, above the soil surface, in order to apply the pile head loading, as depicted on Figure 6. Moreover, in order to facilitate the analysis in terms of bending moments generated in the pile during the lateral loading, a vertical beam made of 20 structural elements is generated in the pile axis (Figure 6). This beam has low $\mathrm{E}_{\mathrm{b}}$ and $\mathrm{I}_{\mathrm{b}}$ characteristics (compared to $\mathrm{E}_{\mathrm{p}}$ and $\mathrm{I}_{\mathrm{p}}$ values), in order not to affect the pile bending stiffness, but has the same deflection as the pile. According to the Bernoulli beam theory, the pile bending moment $M_{p}$ is then equal to $M_{b} \times\left(E_{p} \times I_{p}\right) /\left(E_{b} \times I_{b}\right)$, where $M_{b}$ is the bending moment directly recorded in the numerical model using the beam element. Interfaces are generated between the pile and the soil (at the pile shaft and toe).

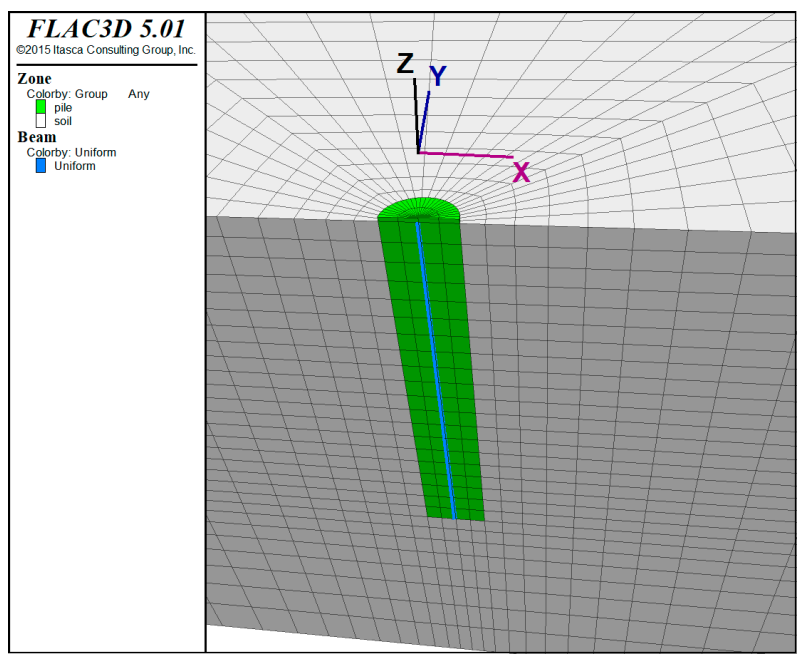

Figure 6. Numerical modelling of the pile.

\subsection{Constitutive Models}

When dealing with a soil-structure interaction problem using numerical modelling in a continuum, the choices of material and interface constitutive models and the calibration of their parameter are essential.

As already discussed, the pile-soil interaction behaviour is highly influenced by the rigidity of the pile, characterized by $\left(E_{p} \times I_{p}\right)$ value. The pile is simulated by volume element with an elastic behaviour and an equivalent Young modulus equal to $31 \mathrm{GPa}$. The Poisson's ratio is taken equal to 0.3 .

Concerning the modelling of the soil behaviour, to overcome the limitations of the classical elastic-perfectly plastic model with Mohr-Coulomb failure criteria, a friction hardening elastoplastic model, with shear-induced volumetric changes and stress-dependent stiffness, was implemented is this study. The Flac3D built-in "CHsoil" model was used [25]. This model permits to account for a higher soil stiffness during unloading-reloading process and for a soil stiffness dependent on the initial stress state. Indeed, the initial stress state significantly increases from the head of the pile, at the mudline, to the toe at $10 \mathrm{~m}$ depth, actually leading to variation in soil stiffness along the pile. To calibrate the soil model elastic stiffness parameters, an average value of a deformation modulus equal to $50 \mathrm{MPa}$ and Poisson's ratio equal to 0.2 (i.e., a bulk modulus $K_{\text {ref }}=27.8 \mathrm{MPa}$ and shear modulus $G_{r e f}=20.8 \mathrm{MPa}$ ) are targeted at a mid-depth of $5 \mathrm{~m}$, where the initial mean effective pressure is equal to $p^{\prime}{ }_{m}=30 \mathrm{kPa}$, also set as the reference pressure $p_{\text {ref. }}$. In CHsoil model, the elastic bulk and shear modulus are then computed using Equations (7) and (8) according to the initial mean effective pressure $p_{m}^{\prime}$, which increases with depth due to soil 
weight. With $\mathrm{m}=\mathrm{n}=0.5$, at a depth $10 \mathrm{~m}$, the elastic deformation modulus is equal to $70 \mathrm{MPa}$ :

$$
\begin{aligned}
& K^{e}=K_{r e f} \cdot p_{r e f}\left(\frac{p_{m}^{\prime}}{p_{r e f}}\right)^{m} \\
& G^{e}=G_{r e f} \cdot p_{r e f}\left(\frac{p_{m}^{\prime}}{p_{r e f}}\right)^{n}
\end{aligned}
$$

The CHsoil model parameters used in this study are given in Table 2 and the corresponding behaviour obtained on triaxial compression tests at 30 and $50 \mathrm{kPa}$ of confinement are depicted on Figure 7, with an unloading-reloading loop.

However, this model is not able to account for specific features of sand behaviour under a high number of load cycles (strain accumulation due to fatigue, etc.), as there is only an isotropic shear hardening mechanism. Indeed, as this numerical study first aims at developing a complex loading procedure (multi-directional cyclic lateral loading), the efforts were not concentrated on implementing a constitutive model with a high degree of complexity, and this aspect is part of the numerical work perspectives.
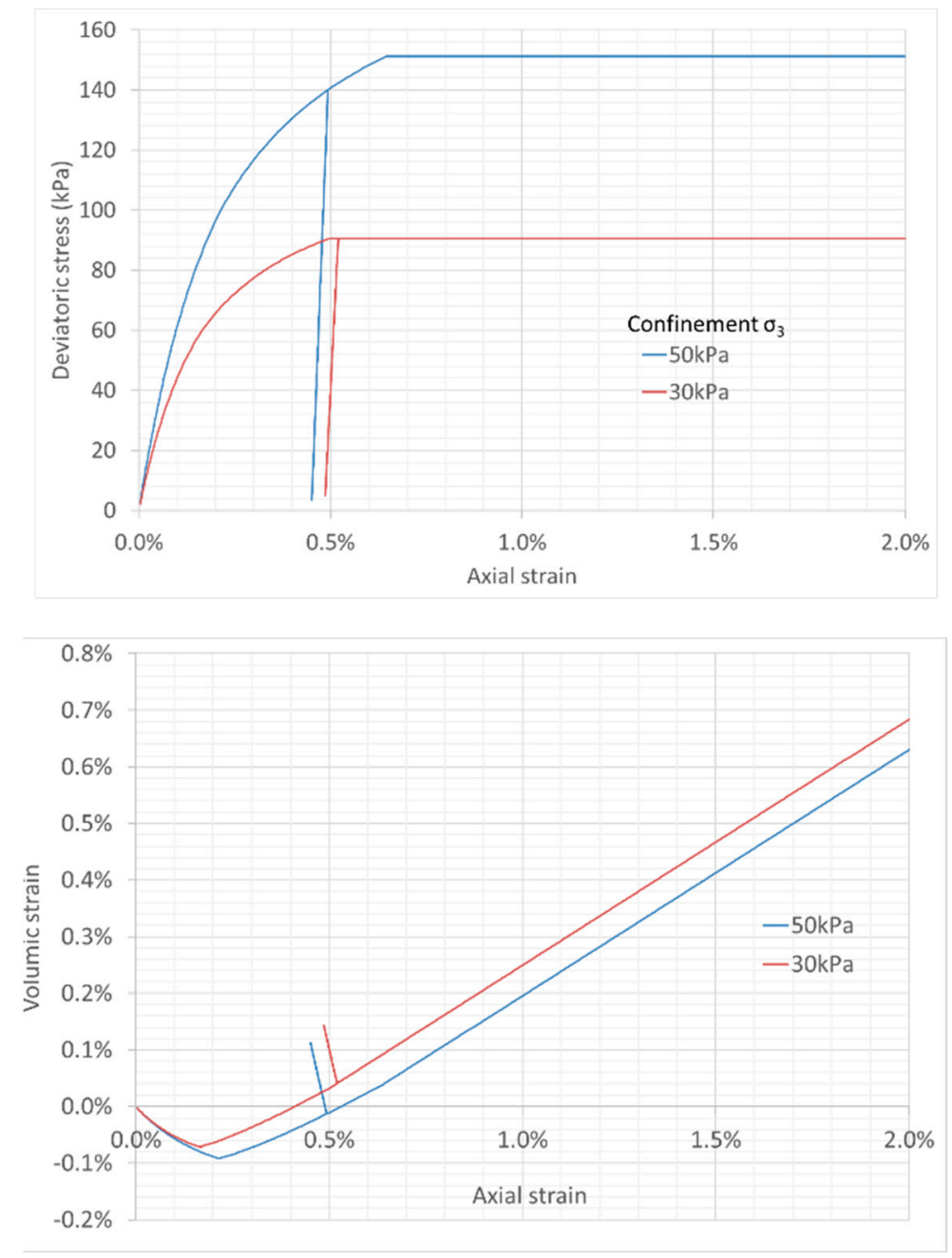

Figure 7. Triaxial numerical test results with CHsoil. 
Table 2. Parameters of the CHsoil model.

\begin{tabular}{ccc}
\hline Parameter & Significance & Value \\
\hline $\mathbf{p}_{\mathbf{r e f}}$ & Reference pressure & $30 \mathrm{kPa}$ \\
$\mathbf{E}_{\mathbf{r e f}}$ & Deformation modulus number & $1680^{1}$ \\
$\boldsymbol{v}$ & Poisson's ratio & 0.2 \\
$\mathbf{m}$ & Bulk modulus exponent & 0.5 \\
$\mathbf{n}$ & Shear modulus exponent & 0.5 \\
$\boldsymbol{\varphi}_{\mathbf{f}}$ & Maximum friction angle & $37^{\circ}$ \\
$\mathbf{R}_{\mathbf{f}}$ & Failure ratio & 0.9 \\
$\boldsymbol{\varphi}_{\mathbf{c v}}$ & Constant volume friction angle & $30^{\circ}$ \\
$\mathbf{c}$ & Cohesion & $0 \mathrm{kPa}$ \\
$\mathbf{\Psi}_{\mathbf{f}}$ & Maximum dilation angle & $7^{\circ}$ \\
\hline
\end{tabular}

${ }^{1}$ The deformation modulus for the reference pressure is then equal to $\mathbf{E}_{\text {ref }} \cdot \mathbf{p}_{\text {ref }}=50.4 \mathrm{MPa}$.

Interfaces are placed between the soil and the pile by using the standard interface feature from the software. The interfaces are characterized by normal and shear stiffness and sliding properties. The interface normal stiffness $k_{n}$ and shear stiffness $k_{s}$ are computed equal to $1.2 \mathrm{GPa} / \mathrm{m}$, according to the adjacent zone size and stiffness, in order to optimize the computational time [22], so they have no real physical meaning. The interfaces have no cohesion and a friction angle equal to $2 / 3$ of the soil ultimate friction angle, i.e., equal to $2 / 3 \times 37^{\circ}=24.7^{\circ}$, which is a conventional friction angle for a relatively rough soilsteel interface.

\subsection{General Modelling Procedure}

A lateral pile loading simulation follows the subsequent steps:

(1) Mesh generation for the ground mass, the pile and the interfaces. The pile is first generated separately above the soil mass, and is then moved down into its final position, in order to correctly create the contact with the interfaces [22]. The pile is thus numerically wished-in-place and the possible pile installation effects are therefore not represented. Moreover, this procedure would correspond to the case of a close-ended rather than an open-ended pile.

(2) Stepping until reaching static equilibrium under gravity and soil self-weight. The zones occupied by the future pile are first considered as soil. The calculation is performed under drained conditions, so the submerged unit weight $\gamma^{\prime}=10.2 \mathrm{kN} / \mathrm{m}^{3}$ is assigned to the zones and an earth coefficient $\mathrm{K}_{0}=0.5$ is used to initialize the horizontal effective stress. Static equilibrium is considered reached when the unbalanced force ratio is below $10^{-6}$. This ratio is defined as the largest ratio between the maximum grid-point unbalanced force to the average applied force amongst all of the model grid-points.

(3) The pile zones are assigned pile properties and a new static equilibrium is reached.

(4) The displacements are initialized (at this stage, they are very small and have no physical meaning).

(5) Lateral loading is applied using the procedure described below.

(6) All the calculations are performed in small strain conditions.

\subsection{Loading Procedure}

Due to the formulation of the program Flac3D, a loading can be defined by applying a velocity to model grid-points. This procedure is especially appropriate as the loading (and loading direction) varies during the process. The applied velocity then corresponds to an increment in displacement (in the same direction) at each time-step (of duration $\Delta t$ ) of the stepping process. In the case of a quasi-static study, the velocity has only a numerical signification, and should be sufficiently small in order to keep the model in a quasi-static equilibrium (i.e., with a negligible unbalanced force ratio). The choice of the applied velocity is discussed later. Moreover, numerical damping is introduced in the computational process to reach a quasi-static equilibrium state (combined damping is used in this study). 
To apply a horizontal force at the head of the pile, a horizontal velocity is therefore applied to all pile head grid-points (on the $0.1 \mathrm{~m}$ thick pile slice above the mudline). Nevertheless, the process is governed in terms of force value, by implementing adequate servo files that compute the current resulting force at pile head during the process and then adapts the required velocity accordingly (in particular, its direction). The current force at the pile head is computed as the sum of the unbalanced forces of all the grid-points of the pile head where the velocity is applied (in the $\mathrm{x}$ direction to obtain the force in $\mathrm{x}$ direction $\mathrm{H}_{\mathrm{x}}$ and in the $\mathrm{y}$ direction to compute $\mathrm{H}_{\mathrm{y}}$, where applicable, i.e., for the multi-directional loading case).

Two types of loading procedures are implemented: for mono-directional lateral loading (only in the $\mathrm{x}$ direction) and multi-directional lateral loading (in $\mathrm{x}$ and $\mathrm{y}$ directions).

\subsubsection{Loading Procedure for Mono-Directional Monotonic Loading and Cyclic Loading}

A velocity is applied on the pile head only in $\mathrm{x}$-direction, and due to geometrical and material symmetry of the model, it induces a pile head horizontal force in the $x$ direction. The impact of the numerical value of the velocity on the model response was the subject of a parametric study [24] and a value equal to $5 \cdot 10^{-8}(\mathrm{~m} / \mathrm{step})$ permitted to maintain an acceptable quasi-static equilibrium during the loading process (i.e., negligible maximum unbalanced force), with a reasonable computational time. Horizontal loading is accomplished with a positive velocity in the $\mathrm{x}$ direction (pile head displacement in positive $x$ direction, see axes in Figures 5 and 6 ), until the desired $\mathrm{H}_{\max }$ value; then, unloading is performed by applying a velocity in the opposite direction (-x) until the desired $\mathrm{H}_{\min }$ value. The velocity was set to $1 \cdot 10^{-8}$ (m/step). Reloading and unloading loops are applied in the same manner. Twenty cycles were applied for each calculation (under mono-directional loading, system behaviour was considered unaffected after around 20 cycles, see Section 3).

Under lateral monotonic loading, with a PC (CPU $1.9 \mathrm{GHz}-\mathrm{RAM} 16 \mathrm{Go}$ ), the computation duration was approximately $2 \mathrm{~h}$ to reach $\mathrm{H}=1.77 \mathrm{MN}$ and 9 more hours were needed to reach a pile head displacement equal to $0.15 \mathrm{D}(\mathrm{H}=3.46 \mathrm{MN})$, on the half model. The computation time is directly proportional to the applied velocity value. Concerning the cyclic loading, achieving 20 loops of unloading-reloading took about $20 \mathrm{~h}$ for case 1 and $48 \mathrm{~h}$ for case 7 (as the computation time is directly correlated to the pile head displacement, for a given applied velocity).

\subsubsection{Loading Procedure for Multi-Directional Cyclic Loading}

Concerning a multi-directional horizontal loading process as described in Section 2.1, a specific procedure has been developed in the frame of this work, in order to apply a given loading path, but controlled in terms of displacements. Indeed, the complexity lies in the fact that force vectors and displacement vectors increments are not co-linear.

The first loading is applied using the mono-directional procedure (but on the full model), until $\mathrm{H}_{\max }$ value is reached at pile head.

Concerning the unloading, the resulting horizontal value $\mathrm{H}$ is considered varying linearly according to the azimuth $\omega$ (Figure 3) from $\mathrm{H}_{\max }$ down to $\mathrm{H}_{\min }$, for $\omega=0$ to $\omega_{\max }=30^{\circ}$. The horizontal force $\mathrm{H}$ has two components: $\mathrm{H}_{\mathrm{x}}=\mathrm{H} \cos \omega$ and $\mathrm{H}_{\mathrm{y}}=\mathrm{H} \sin \omega$, as shown on Figures 8 and 9a) depicts the imposed velocity for unloading (xvel negative to decrease $\mathrm{H}_{\mathrm{x}}$ and yvel positive to increase $\mathrm{H}_{\mathrm{y}}$ ). The absolute value of the norm of the velocity vector is kept constant (vel $=5 \times 10^{-8} \mathrm{~m} /$ steps as a cruise value, after a ramp of increase) but the orientation (angle $\beta$ ) of the velocity vector is adjusted during the calculation, in order to follow the imposed path in terms of force $H=f(\omega)$. The initial value for $\beta$ is arbitrarily picked at $45^{\circ}$ and the $x$ and y component of the velocity (xvel and yvel) are re-calculated based on current $\beta$ value at each step (xvel $=\operatorname{vel} \times \cos \beta$, yvel $=$ vel $\times$ $\sin \beta$ ). On Figure 10, the angle $\delta$ is defined as the azimuth of the resulting horizontal force at the current step (step n), whereas the targeted azimuth is $\omega$ (computed according to the current $\mathrm{H}$ value and given function $\mathrm{H}=\mathrm{f}(\omega))$. The difference is $\Delta \omega=\omega-\delta$. For the next step $(n+1)$, the orientation of velocity is then adjusted to correct the orientation of the 
force. The new value of $\beta$ is computed with $\beta_{\mathrm{n}+1}=\beta_{\mathrm{n}}+\Delta \beta$, with $\Delta \beta=\Delta \omega$. During the whole process, the adjusting angle $\Delta \beta=\Delta \omega$ actually oscillates around zero. The unloading process stops when the horizontal force $\mathrm{H}$ reaches $\mathrm{H}_{\min }$.

The same concept is implemented for reloading, by inverting the sign of xvel and yvel (Figure $9 b$ ) and with $\Delta \beta=-\Delta \omega$. The norm of velocity vector is also equal to $5 \times 10^{-8}$ $\mathrm{m} / \mathrm{steps}$ as a cruise value, after a ramp of increase. The reloading process stops when the horizontal force $\mathrm{H}$ reaches $\mathrm{H}_{\max }$; then a new unloading-reloading loop is achieved. This cyclic process is applied for 40 loops (compared to the mono-directional loading, 20 additional cycles had to be applied to confirm the trend observed after approximately the ten first cycles (see Results Section).

The computation of the first 20 cycles took about 6.5 days with the same PC.

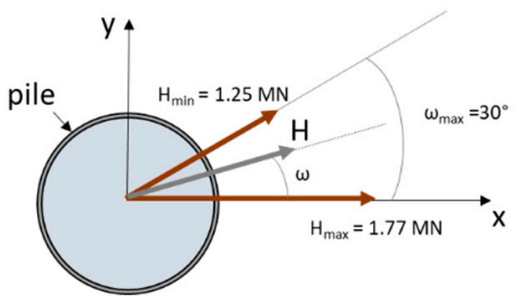

Figure 8. Force applied on the pile head.

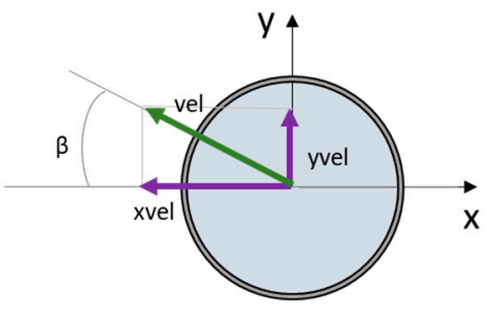

a) Multi-dir. unloading: decrease $H_{x}$ - increase $H_{y}$

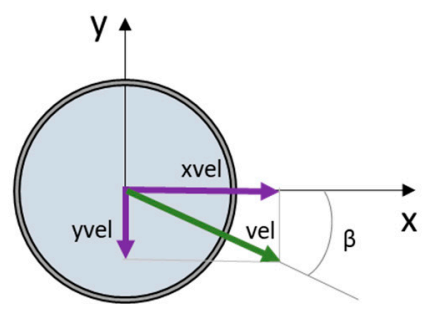

b) Multi-dir. reloading: increase $H_{x}$ - decrease $H_{y}$

Figure 9. Nodal velocity applied on the pile head for multi-directional (a) unloading; and (b) reloading.

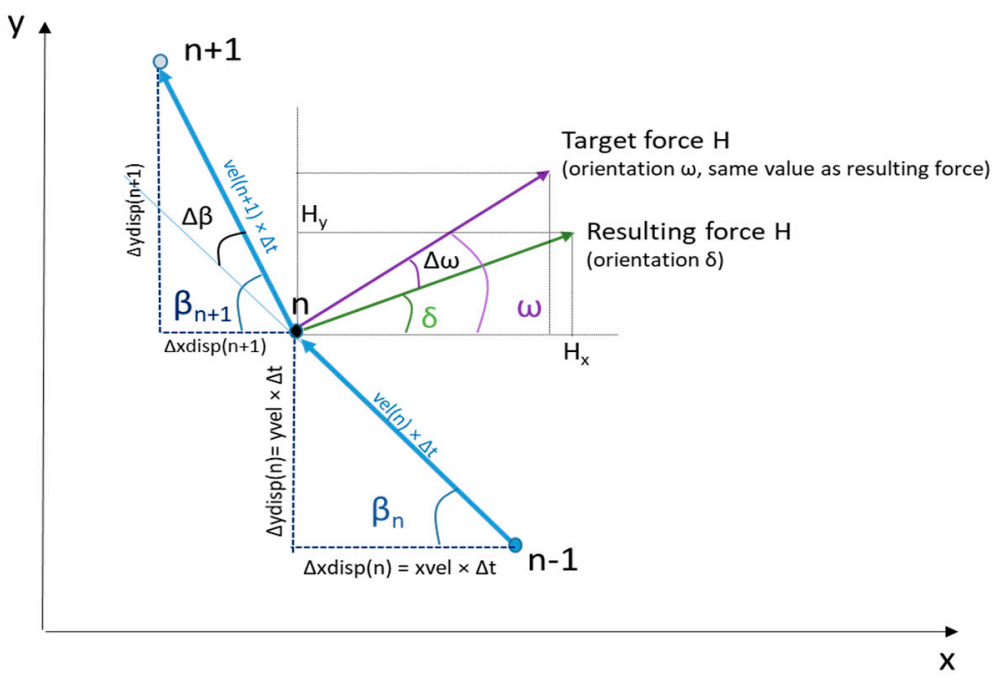

Figure 10. Numerical procedure for multi-directional unloading.

\section{Results}

\subsection{Monotonic Lateral Loading}

The preliminary calculation consists in the mono-directional and monotonic lateral loading of the pile, to assess the conventional lateral limit load $\left(\mathrm{H}_{\text {lim }}\right)$. Indeed, the effect of the cyclic loading is supposed to be more important when the maximum applied force 
$\mathrm{H}_{\max }$ becomes closer to the limit load $\mathrm{H}_{\text {lim }}$. The ratio $\mathrm{H}_{\max } / \mathrm{H}_{\text {lim }}$ should then necessarily intervene in the cyclic degradation of the behaviour. Several procedures exist to determine $\mathrm{H}_{\text {lim }}$ value: the convention chosen here is the horizontal force that corresponds to a horizontal head displacement equal to $25 \%$ of the pile diameter D (with $\mathrm{D}=1.7 \mathrm{~m}$ ). Figure 11 shows $\mathrm{H}_{\text {lim }}=4.3 \mathrm{MN}$ (by extrapolating the numerical results that were stopped for a displacement equal to $0.15 \mathrm{D}=0.255 \mathrm{~m}$.

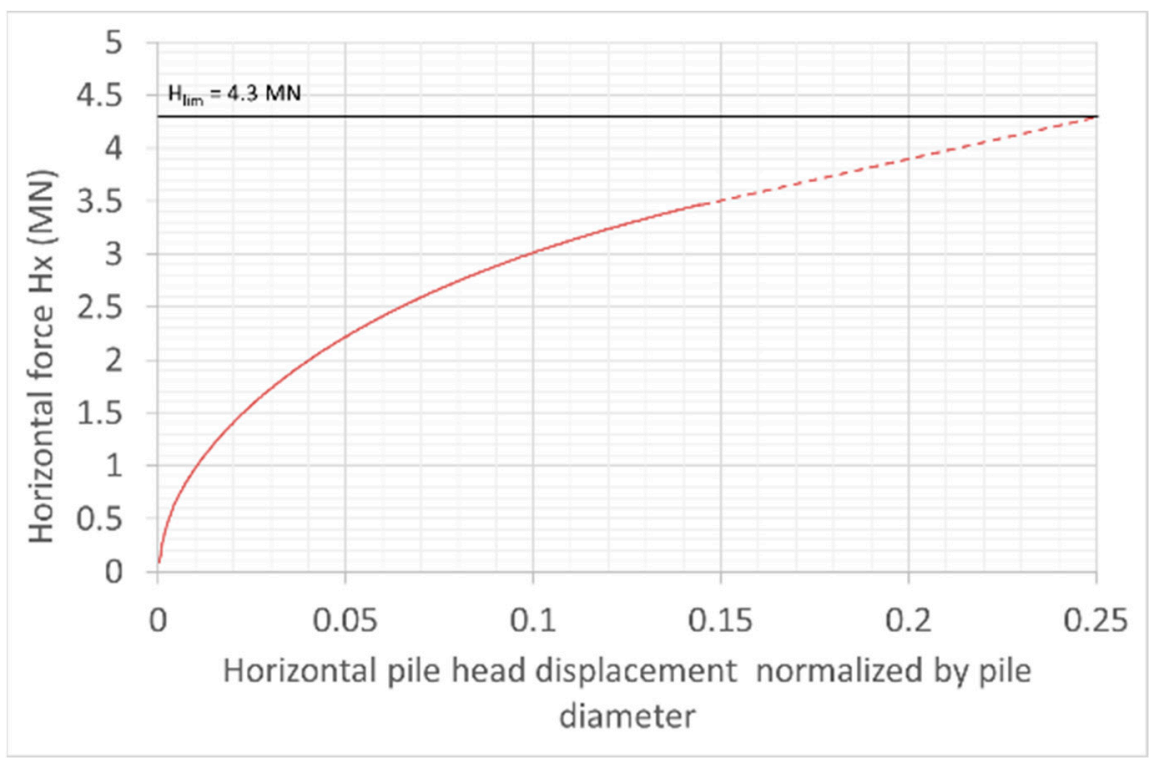

Figure 11. Force-displacement curve for the monotonic lateral loading of the pile.

\subsection{Mono-Directional Lateral Cyclic Loading}

Figure 12 presents the horizontal force developed at the pile head $\left(\mathrm{H}=\mathrm{H}_{\mathrm{x}}\right)$ according to the pile head displacement, for the reference case (case 1) of mono-directional cyclic loading. Twenty cycles of unload and reload were applied. This figure shows that the irreversible horizontal displacement increases after each cycle, with a decreasing rate all along the cycles. The pile deflection is depicted in Figure 13a. The pile is mainly subjected to rotation around a fixed point located at a depth of $8 \mathrm{~m}$ (with an angle of rotation of around $0.3^{\circ}$ when the horizontal force is equal to $1.77 \mathrm{MN}$ ), but also to bending, leading to a bending moment in the pile (Figure $13 \mathrm{~b})$. The bending moment is maximum $\left(\mathrm{Mf}_{\max }\right)$ at a depth around $4-4.5 \mathrm{~m}$ and only increases by around $1 \%$ from the first loading at $\mathrm{H}_{\max }=1.77 \mathrm{MN}\left(\mathrm{Mf}_{\max \_0}=4.40 \mathrm{MN} \cdot \mathrm{m}\right)$ to the 20 th cycle $\left(\mathrm{Mf}_{\max \_20}=4.44 \mathrm{MN} \cdot \mathrm{m}\right)$. The pile deflection curve also shows that pile displacement accumulation mainly occurs at the pile head, and the pile toe has a negligible backward displacement accumulation along the cycles.
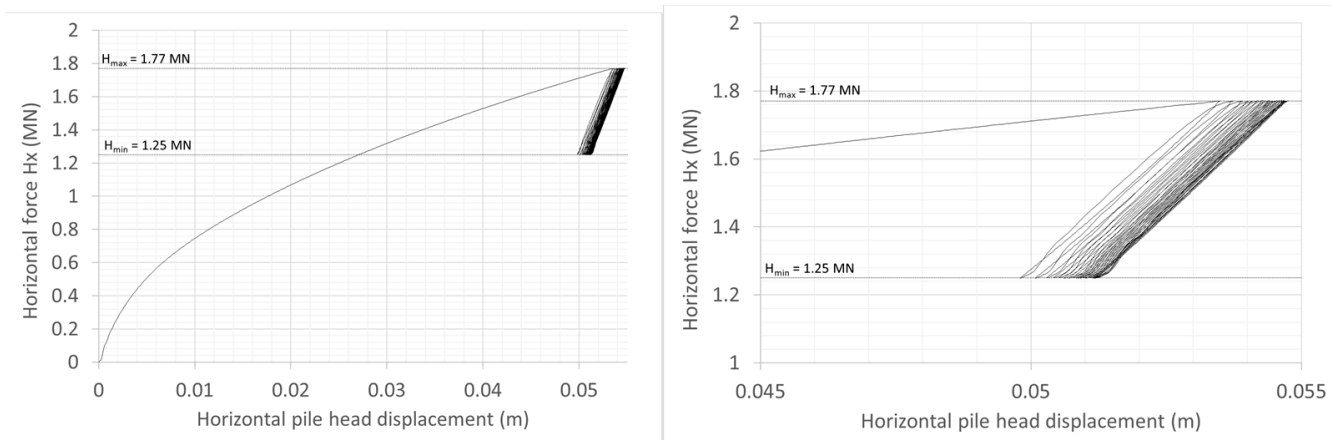

Figure 12. Force-displacement curve for mono-directional lateral cyclic loading (reference case, case 1). 

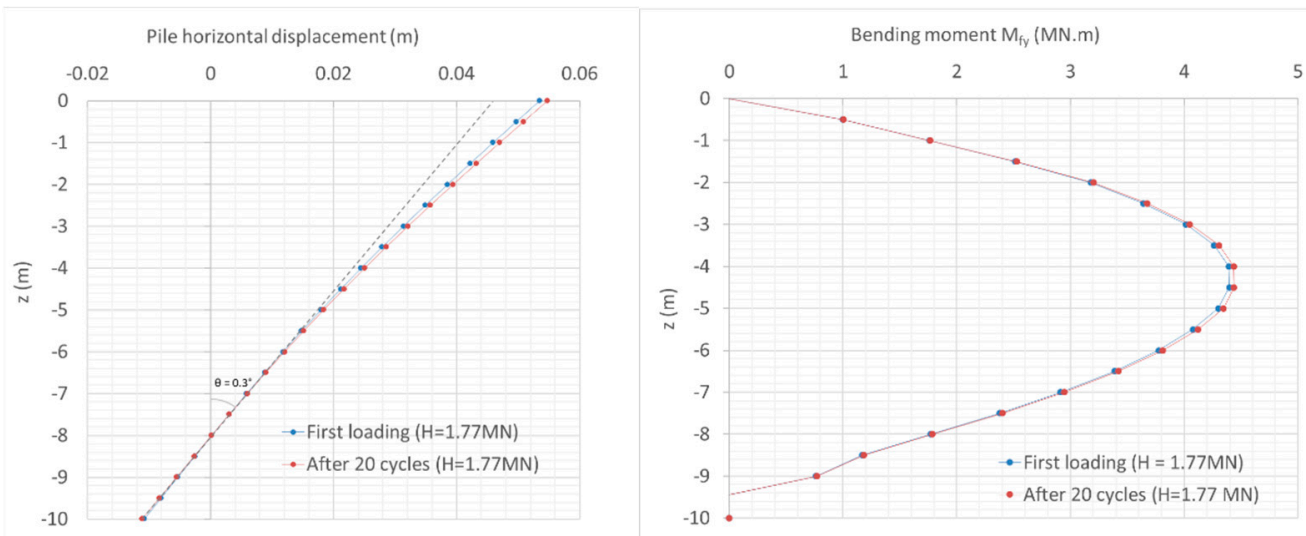

Figure 13. Pile horizontal displacement and bending moment ( $\mathrm{CH} 1$ case).

The increase in horizontal pile head deflection $\left(\Delta y=y_{N}-y_{1}\right)$ normalized by the first loading displacement at $\mathrm{H}_{\max }\left(\mathrm{y}_{1}\right)$ is drawn according to the cycle number $\mathrm{N}$ in the natural $\operatorname{logarithm}(\operatorname{lnN})$ in Figure 14. From the law proposed by Lin and Liao (1999) (Equation (1)): $\mathrm{y}_{\mathrm{N}} / \mathrm{y}_{1}-1=\alpha \ln \mathrm{N}$; the parameter $\alpha$ can be obtained. The numerical results approximately verify the logarithmic law and an $\alpha$ value equal to 0.008 was obtained for the reference case. Figure 14 also shows the head displacement results obtained for case 7 (case with the largest average force and cyclic amplitude), leading to $\alpha=0.017$. The values of the parameter $\alpha$ obtained for all the investigated cases are summarized in Figure 15. This figure highlights that the higher the cyclic amplitude, the larger the $\alpha$ value; however, for a given cyclic amplitude, the average force has no impact on $\alpha$.

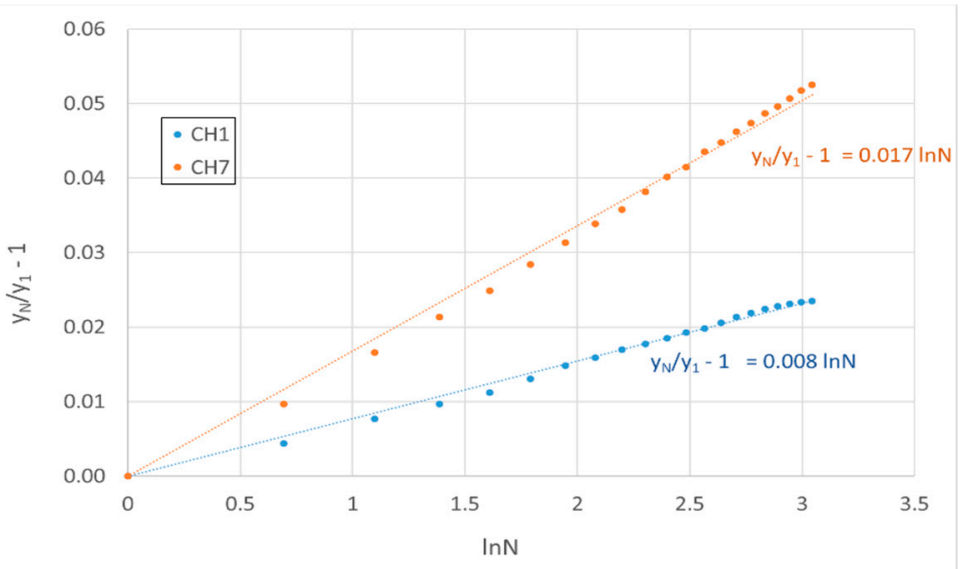

Figure 14. Accumulation of pile head displacement during the cycles and linear approximation with the law $\mathrm{y}_{\mathrm{N}} / \mathrm{y}_{1}-1=\alpha \ln \mathrm{N}$.

For all the cases investigated, the pile is subjected to a rotation around a fixed point, all along the cycles located at a depth of $8 \mathrm{~m}$, as depicted in Figure 16 for cases 1 and 7 . Figure 17 depicts the relative increase in the maximum bending moment obtained in the pile for $\mathrm{H}_{\max }$ during the 20 cycles. The increase is limited for all the cases $(0.2-2.4 \%)$, but it is higher for a larger cyclic amplitude, whereas the average force has no impact. 


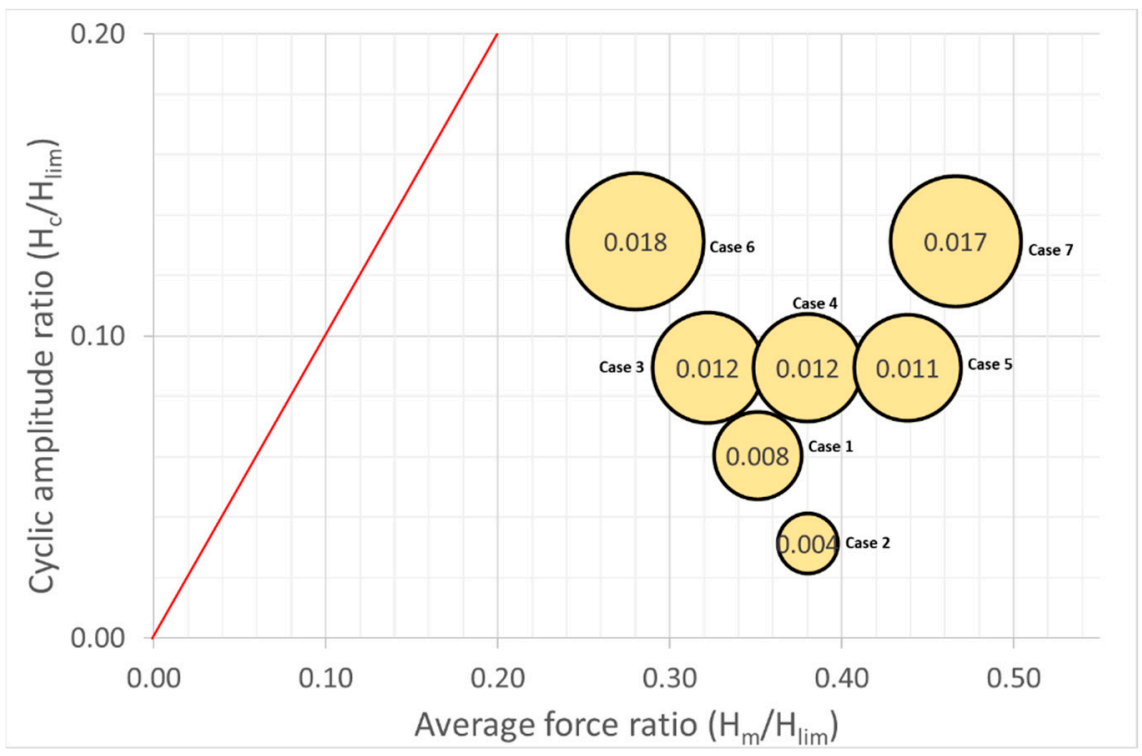

Figure 15. Parameter $\alpha$ from the law $\mathrm{y}_{\mathrm{N}} / \mathrm{y}_{1}-1=\alpha \ln N$.

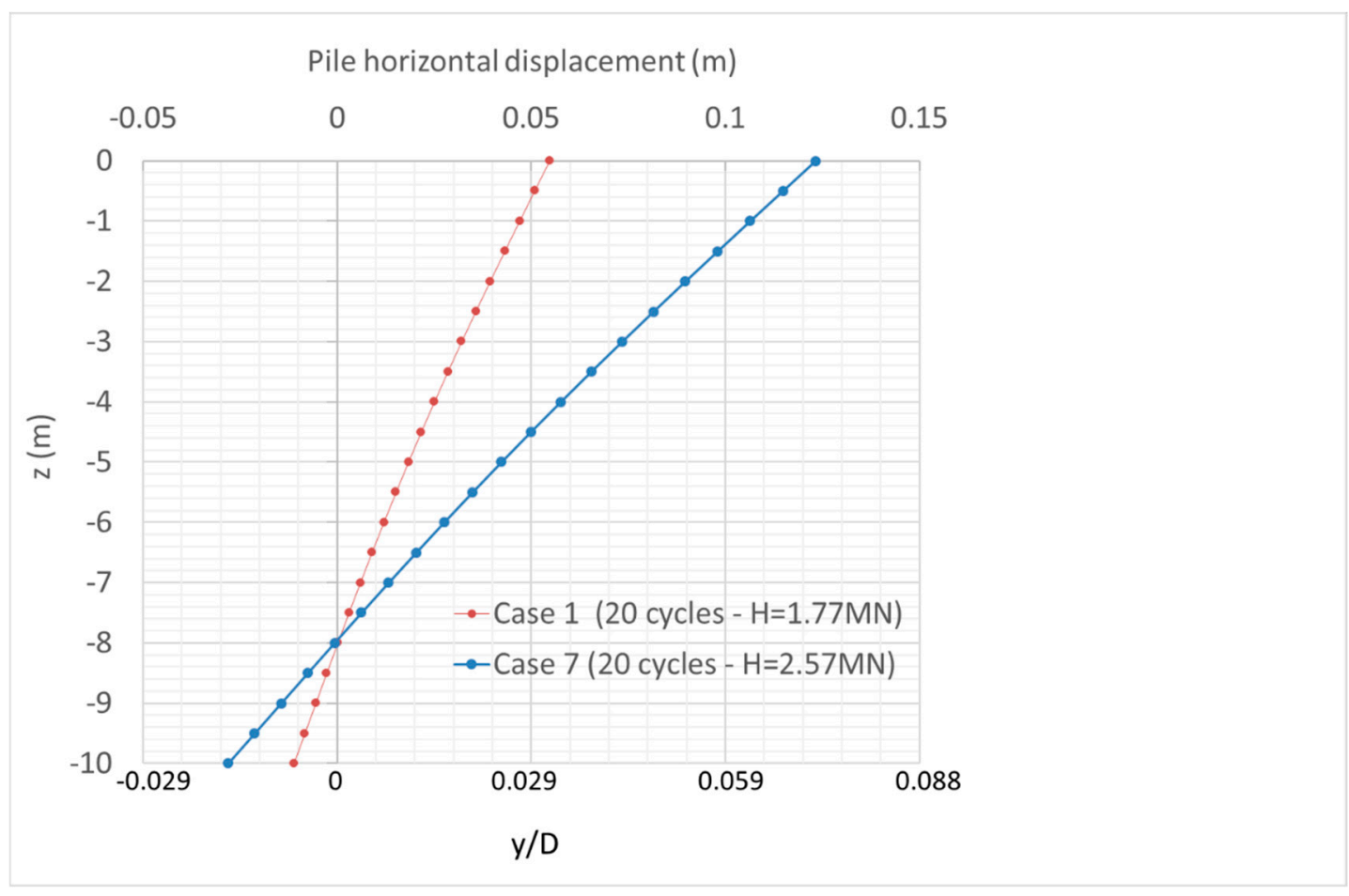

Figure 16. Pile horizontal displacement after 20 cycles for case 1 (reference) and case 7 (displacement of the nodes located along the pile axis).

\subsection{Multi-Directional Lateral Cyclic Loading}

The curve shown on Figure 18 (horizontal force in y direction $\mathrm{H}_{\mathrm{y}}$ vs. horizontal force in $\mathrm{x}$ direction $\mathrm{H}_{\mathrm{x}}$ ) is a numerical result taken from the simulation under multi-directional cycling loading. It demonstrates that the implemented procedure, described in Section 2.5.2, successfully permits applying the targeted loading path. This figure also reminds that the same unloading and reloading path is trailed along the cycles. 


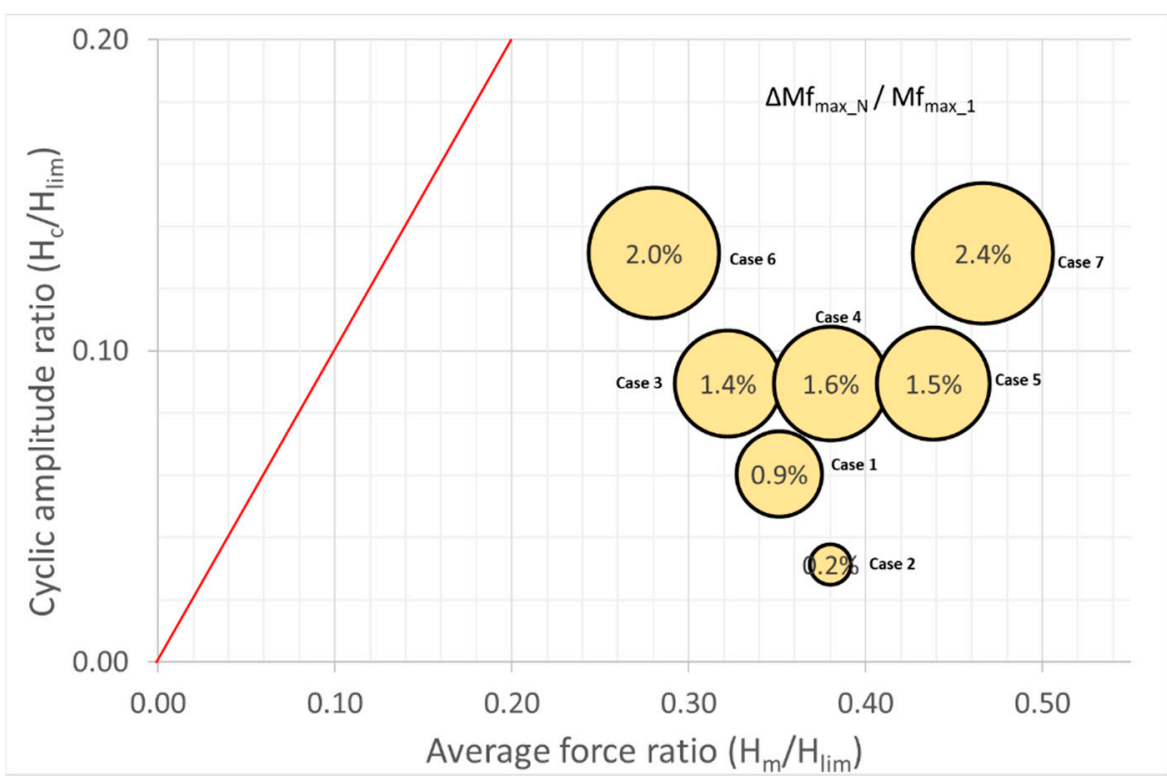

Figure 17. Increase in the maximum bending moment $\left(\mathrm{M}_{\mathrm{fmax}}\right)$ in the pile from the first loading $\left(\mathrm{Mf}_{\max \_1}\right.$ for $\left.\mathrm{H}_{\max }\right)$ to the 20th loading (increase is defined as $\left.\Delta \mathrm{Mf}_{\max \_\mathrm{N}} / \mathrm{Mf}_{\max \_1}\right)$.

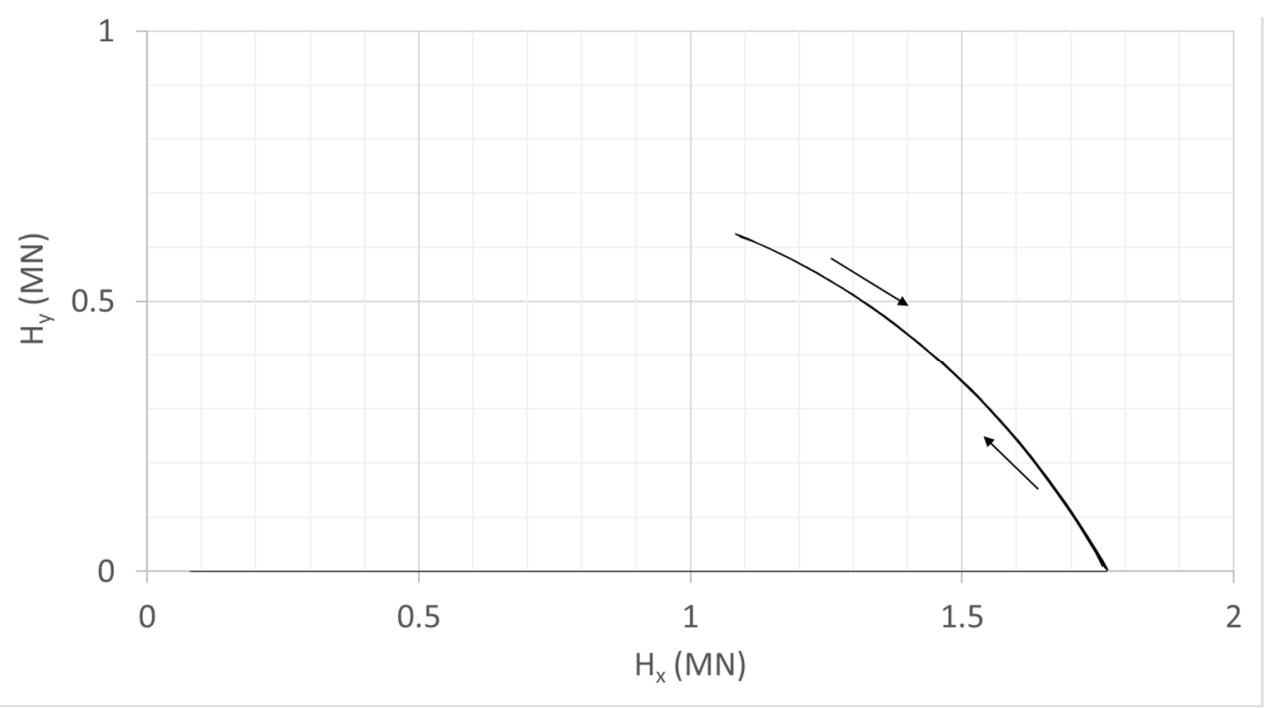

Figure 18. Loading path for the multi-directional cyclic loading simulation.

Figure 19 depicts the evolution of the pile head displacement in the $\mathrm{x}$ direction during the lateral multidirectional cyclic loading between $\mathrm{H}=1.25$ and $1.77 \mathrm{MN}$, whereas Figure 20 is a plan view of the pile head displacement. The latter highlights that the pile head is subjected to a horizontal displacement accumulation in both the $\mathrm{x}$ and $\mathrm{y}$ directions during the loading cycles. Thereby, residual pile displacements occur in the deviated direction (y direction), whereas the horizontal force only goes back to an $\mathrm{x}$ component at each cycle (azimuth $\omega=0^{\circ}$ ). The deviation angle is defined in Figure 20 as $\Omega$. The final deviation angle $\Omega$, for $H=H_{x}$ after 20 cycles (final position of the pile compared to the $\mathrm{x}$ axis) is equal to $4.3^{\circ}\left(\Omega_{\mathrm{L} 20}\right)$. The value of this angle is $\Omega_{\mathrm{L}}=2.3^{\circ}$ after the first cycle (Figure 21 ), it increases during the first ten cycles to reach a nearly constant value at the end of each cycle. Figure 20 also shows this angle at the end of each unloading stages $\left(\Omega_{\mathrm{U}}\right)$, i.e., for a loading azimuth $\omega$ equal to $30^{\circ}$. This angle is equal to $7.9^{\circ}$ for the first unloading and also rapidly (after 5-6 cycles) tends to a constant angle of around $9^{\circ}$. The angle difference between unloading and reloading $\Delta \Omega=\Omega_{\mathrm{U}}-\Omega_{\mathrm{L}}$ is constant after about 10 cycles. 


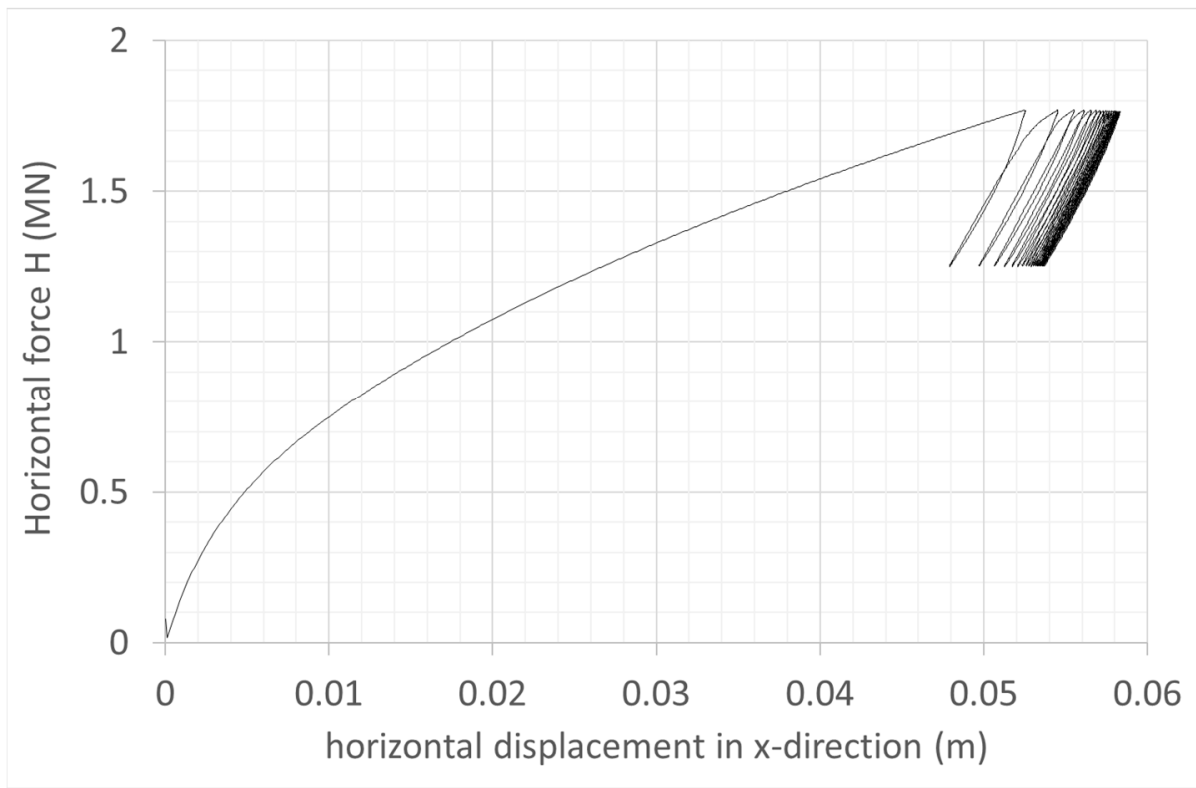

Figure 19. Horizontal applied force (multidirectional) vs. the pile head horizontal displacement in the $\mathrm{x}$ direction.

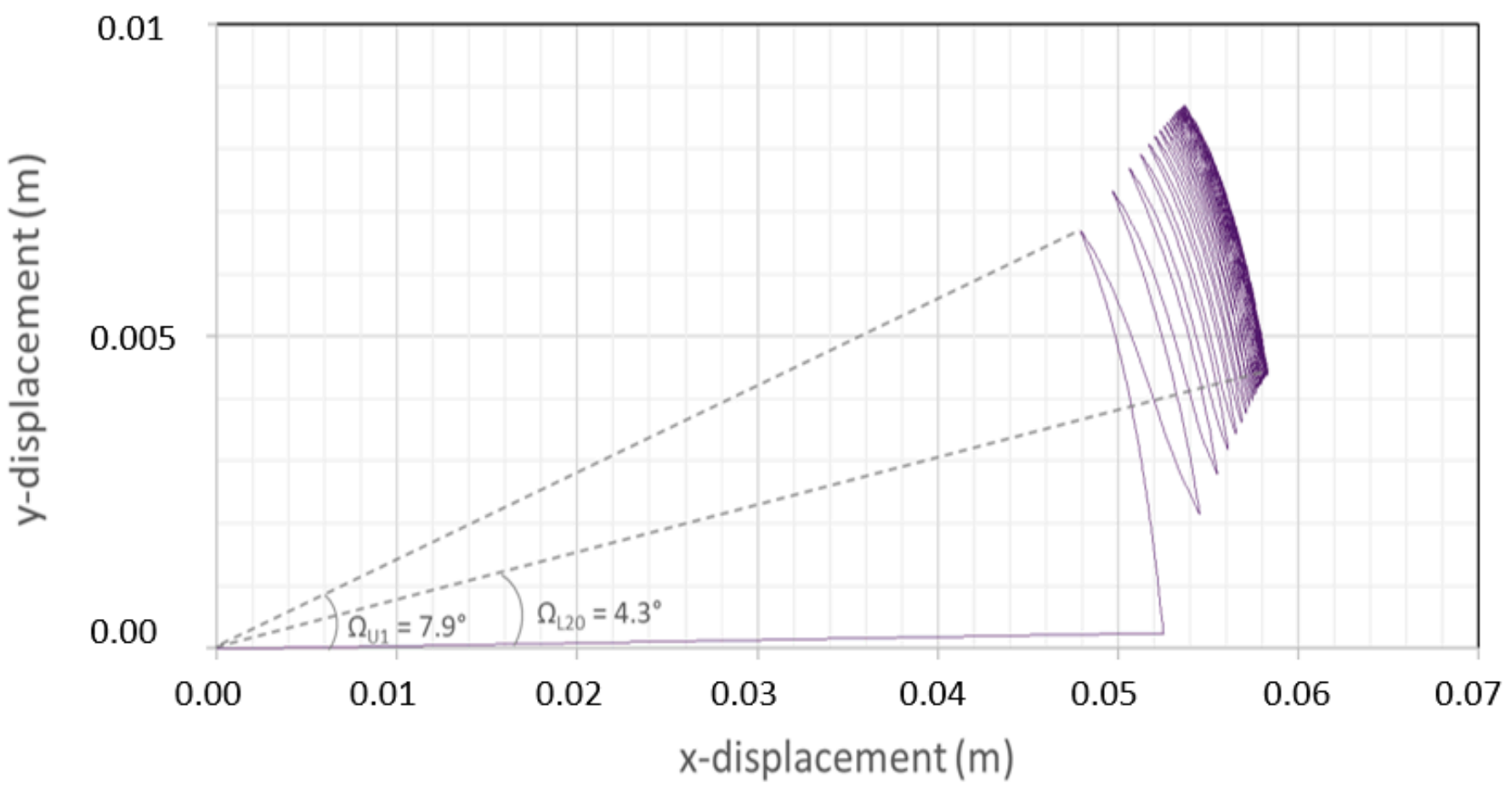

Figure 20. Pile head horizontal displacement during the multi-directional cyclic loading.

Figure 22 presents the horizontal pile head displacement accumulation $\left(\Delta \mathrm{y} / \mathrm{y}_{1}=\right.$ $\left.\mathrm{y}_{\mathrm{N}} / \mathrm{y}_{1}-1\right)$ during the loading cycles (with cycle number $\mathrm{N}$ in natural logarithmic scale), for the multi-directional loading and also for the mono-directional loading of same amplitude (lateral force $\mathrm{H}$ between 1.25 and $1.77 \mathrm{MN}$ ). In the case of the multi-directional loading, the pile head displacement (termed $\mathrm{y}_{\mathrm{N}}$ ) has both $\mathrm{x}$ and $\mathrm{y}$ horizontal components, whereas only a horizontal displacement in $\mathrm{x}$ direction occurs for the mono-directional loading. However, the initial displacement (termed $y_{1}$ ) under the first monotonic loading equal to 1.77 $\mathrm{MN}$ is the same in both calculations $\left(\mathrm{y}_{1}=52 \mathrm{~mm}\right)$. This figure reveals that the pile head displacement accumulation is much larger when cycles are applied with a change 
in loading direction. After 20 cycles, a displacement increase of $11 \%$ was reached for the multi-directional loading, against an increase of only $2 \%$ for the mono-directional loading.

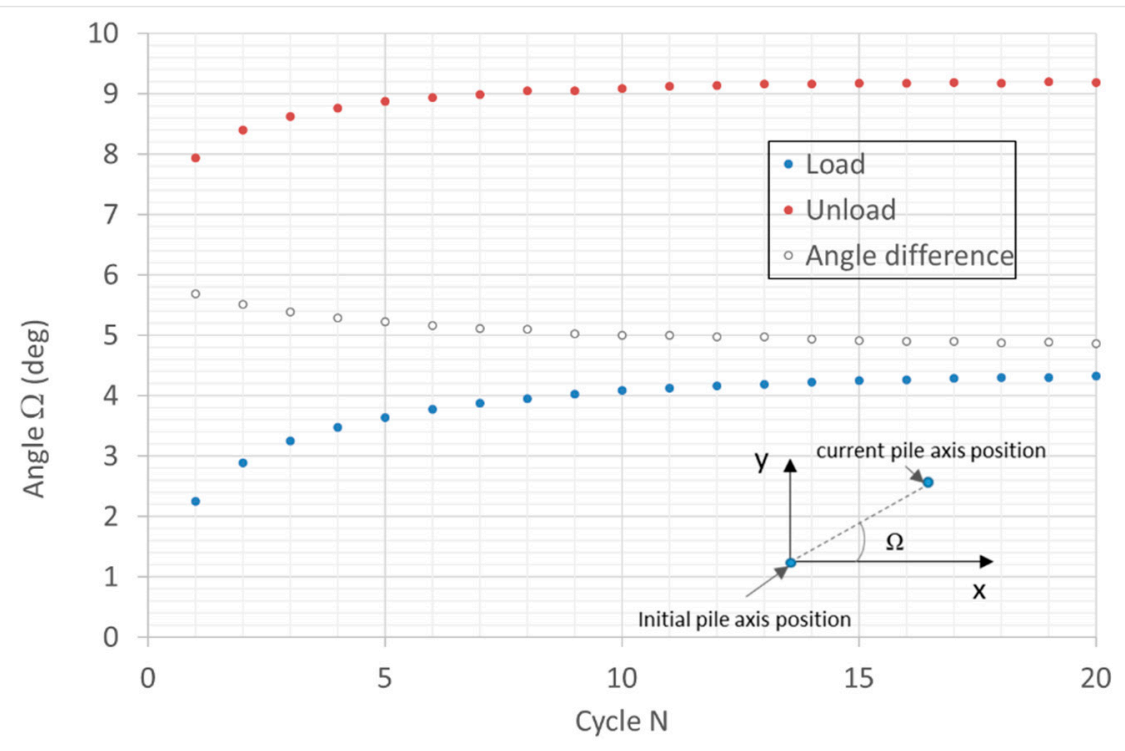

Figure 21. Deviation angle of the pile head horizontal displacement.

This figure also highlights that the accumulation of pile head displacement does not follow the logarithmic law (Equation (2)) anymore when a multi-directional cyclic loading is applied, contrarily to the observation made for the mono-directional loading. However, a linear trend was observed again for a larger amount of cycles (a total of 40 cycles were applied to confirm the trend, as well for the mono-directional loading), with a slope similar to the one obtained under mono-directional loading $(\alpha=0.008)$.

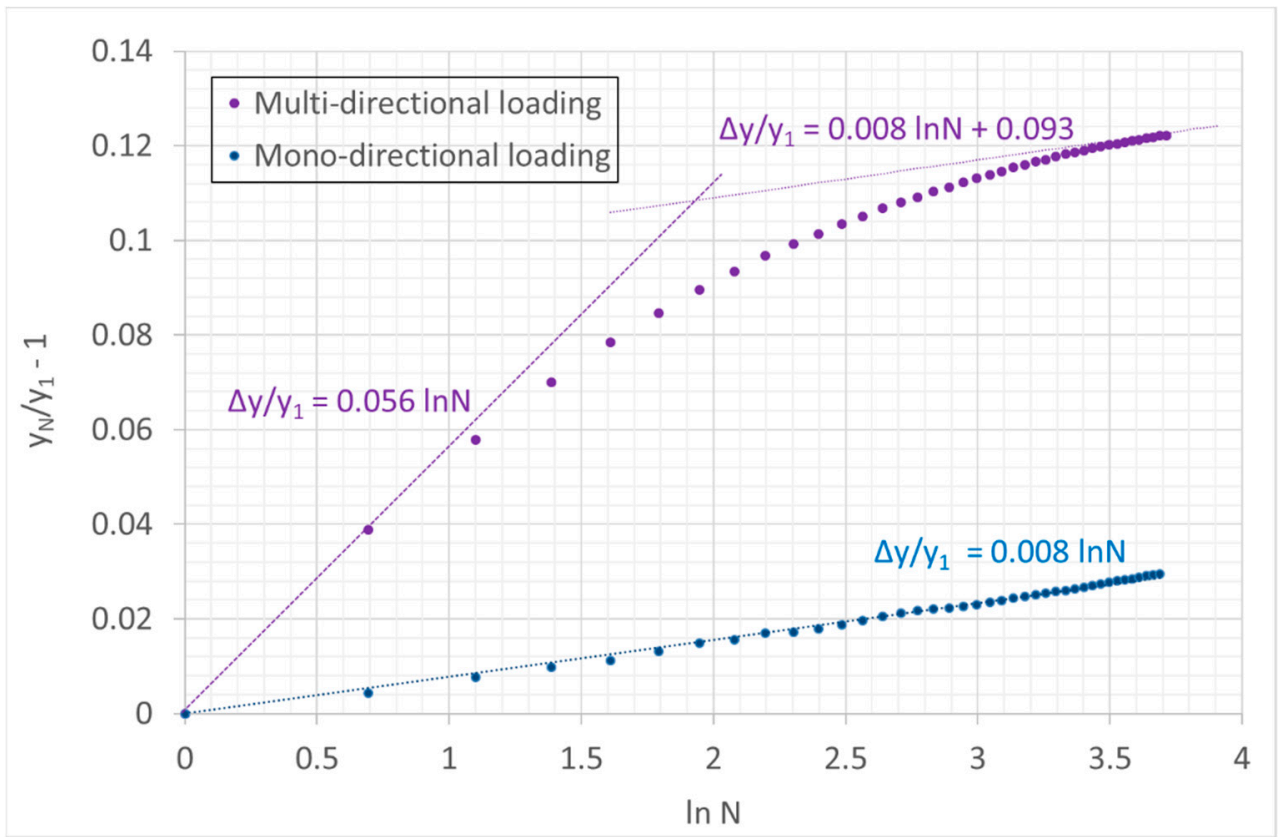

Figure 22. Pile horizontal displacement accumulation during cyclic loading.

\section{Discussion}

The numerical results obtained on the mono-directional lateral cyclic loading are in qualitative good agreement with the predictive logarithmic law for the additional pile head 
displacement (Equations (2) and (3)). The parameter $\alpha$ from the Lin and Lao (1999) [12] law: $\mathrm{y}_{\mathrm{N}} / \mathrm{y}_{1}-1=\alpha \ln \mathrm{N}$ could be obtained and varied between 0.004 and 0.018 mainly according to the cyclic amplitude $\mathrm{H}_{\mathrm{c}}$ for the investigated cases, but, in all likelihood, not according to $\mathrm{H}_{\mathrm{m}}$.

The logarithmic law proposed in the SolCyP recommendation [11] would lead to the expression of the parameter $\alpha$ (from Equations (2) and (3)):

$$
\alpha=0.102 / \mathrm{CR} \times\left(\mathrm{H}_{\mathrm{c}} / \mathrm{H}_{\max }\right)^{0.35}
$$

Thereby, Figure 23 depicts the evolution of $\alpha$ obtained from the numerical results, according to $\left(\mathrm{H}_{\mathrm{c}} / \mathrm{H}_{\max }\right)^{0.35}$, that should lead to a linear relation with a slope $0.102 / \mathrm{CR}$ if Equation (9) is satisfied, with the assumption that the rigidity coefficient $\mathrm{CR}$ (defined in Equation (4)) is independent on the loading. The trend of $\alpha$ increasing with $\left(\mathrm{H}_{\mathrm{c}} / \mathrm{H}_{\max }\right)^{0.35}$ is observed, but the linear relation does not accurately apply. A value of $0.102 / \mathrm{CR}=0.02$ (that satisfies the numerical cases 3, 4 and 5), would lead to $C R=5.1$. However, the rule given by [3] (Equation (1)) with a soil stiffness $E_{s}=50 \mathrm{MPa}$, leads to a flexible pile for $E_{p} I_{p}$ below $1290 \mathrm{MN} \cdot \mathrm{m}^{2}\left(=\left(\mathrm{E}_{\mathrm{p}} \mathrm{I}_{\mathrm{p}}\right)_{\mathrm{fl}}\right)$, then to $\mathrm{CR}=1.6$. According to Equation (9), the parameter $\alpha$ would vary between 0.026 for case 2 and 0.043 for case 6 . These values are thus $2-6$ times higher than the values obtained with the current numerical modelling.

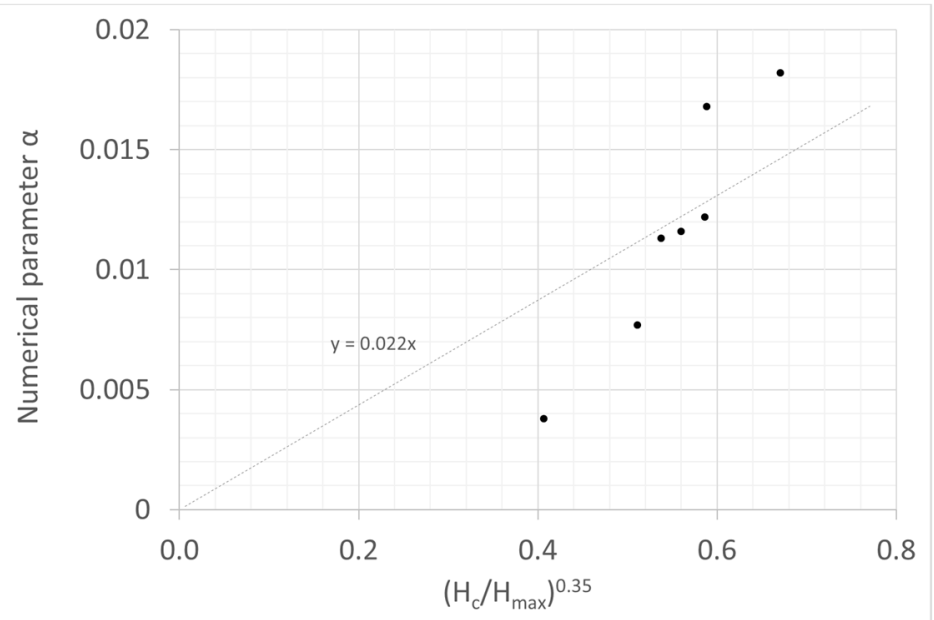

Figure 23. Parameter $\alpha$ obtained on the numerical model according to $\left(\mathrm{H}_{\mathrm{c}} / \mathrm{H}_{\max }\right)^{0.35}$.

The trends given by the proposed numerical model are thus qualitatively acceptable, but it seems that it underestimates the pile head displacement accumulation under lateral mono-directional cyclic loading. This is probably due to the implemented constitutive model for the soil that is not able to take accurately into account the strain accumulation in the soil under repeated loading, and this is a major numerical work perspective to this current study. In fact, the elastoplastic model implemented in this study has only an isotropic hardening shear mechanism, with an elastic response on an unload-reload loop on a triaxial test path (Figure 7), thereby initially not able to take ratcheting effect into account [26]. However, in this soil-structure interaction system, the stress path is more complex than on a pure axisymmetric triaxial test path, leading to stress redistribution in the surrounding soil, to additional plastic zones at following cycles and thus to additional deformations.

As this numerical model accurately represents the qualitative pile-soil interaction behaviour under mono-directional lateral cyclic load, it is implemented to explore the behaviour under multi-directional lateral cyclic loading. This latter requires the implementation of a specific loading procedure. This was successfully done and the numerical model conducted to highlight interesting and encouraging aspects of the specific behaviour 
under a lateral load that varies in its direction during the cyclic process. The main observations are:

- As expected, the pile head displacement suffers a displacement accumulation in both horizontal directions during the cycles, leading to a misalignment of the loading and pile displacement directions;

- The pile head displacements are greatly increased compared to the mono-directional cyclic loading with the same average and cyclic amplitude values. New plastic zones can develop throughout the cyclic loading process as additional deviated displacements go along;

- The pile head displacement does not follow a logarithmic law anymore. The rate of displacement accumulation decreases after about ten cycles, to reach a rate of accumulation similar to the one obtained on the mono-directional loading;

Nonetheless, the effect of the constitutive model on these numerical findings still needs to be highlighted.

In this study, a limited number of cycles of load were applied, as they were all simulated one after the other (cycle-by-cycle simulation). To investigate the behaviour under higher cycle numbers (hundreds, thousands or more), particularly an appropriate constitutive model should be used, but for cycle-by-cycle simulation, as this would lead to a numerical drift of the result along a high number of cycles (accumulation of numerical inaccuracies), as well as a high computational time demand. An alternative approach could be by using a Miner type law [27] or a strain accumulation model [28], that accounts for the accumulation of strains as a function of the number of cycles, relative density and load characteristics. Nevertheless, the applicability to multi-directional cyclic loading still needs to be demonstrated and calibrated for this type of model. The "cycle-by-cycle" numerical approach thus still has a useful future in order to highlight the mechanisms taking place in the system under such a complex loading path.

Moreover, this numerical approach could be extended to a parametric study on the pile bending stiffness (stiffer or more flexible piles compared to surrounding soil), to other loading conditions in terms of average and cyclic amplitude, but also by varying the load history, as it seems to be of high impact on the pile behaviour [26].

\section{Conclusions}

A numerical procedure has been implemented in Flac3D using the program built-in "FISH" language, to apply a multi-directional cyclic lateral loading at pile head. The specific feature lays in the fact that a displacement is applied on the pile head (through a velocity due to the program formulation), that is thus controlled and adjusted based on pile forces conditions to meet the loading direction requirement. The effect of multi-directional loading compared to mono-directional loading has been highlighted, leading to larger pile displacements.

The main numerical work perspective is to perform the simulations with a more complex constitutive model, for instance with kinematic hardening shear mechanism or multi-surface, to account for ratcheting and soil stiffness evolution.

Furthermore, the azimuth amplitude and the loading path followed during the cycles of the multi-directional loading certainly influence the results. The proposed numerical model and developed procedures could be easily implemented to perform simulations under additional and more complex multi-directional loading scenarios. Simulations combining the effects of lateral and vertical cyclic loading could also be performed, to get even closer to the reality of the loading conditions of mutualized anchor foundations for floating wind turbines. 
Author Contributions: Bibliographic review, A.O. and O.J.; conceptualization, F.E., C.D. and O.J.; general methodology, O.J. and F.E.; numerical methodology, O.J. and F.E.; numerical development, O.J.; preliminary numerical parametric study and result analysis, A.O. under the supervision of F.E. and O.J.; final numerical investigation and data curation, O.J.; writing-original draft preparation, O.J.; writing-review and editing, F.E., C.D. and O.J.; validation, F.E. and C.D. All authors have read and agreed to the published version of the manuscript.

Funding: This research received no external funding.

Institutional Review Board Statement: Not applicable.

Informed Consent Statement: Not applicable.

Data Availability Statement: The data presented in this study are available on request from the corresponding author.

Acknowledgments: The authors thank the reviewers for their relevant comments. The characteristics of the numerical model (loading cases and pile geometry) come from discussions with G. Damblans and R. Isorna from France Energies Marines. The authors thank them for these data that permitted to perform a study in a relevant frame, with practical applications.

Conflicts of Interest: The authors declare no conflict of interest.

\section{References}

1. Abadie, C.N. Cyclic Lateral Loading of Monopile Foundations in Cohesionless Soils. Ph.D. Thesis, St Catherine's College University of Oxford, Oxford, UK, 2015.

2. Doherty, P.; Gavin, K. Laterally loaded monopole design for offshore wind farms. Proc. Inst. Civ. Eng. Energy 2012, $165,7-17$.

3. Poulos, H.; Hull, T. The role of analytical geomechanics in foundation engineering. In Foundation Engineering: Current Principles and Practices; ASCE: Reston, VA, USA, 1989; Volume 2, pp. 1578-1606.

4. API. Recommended Practice for Planning, Designing and Constructing Fixed Offshore Platforms—Working Stress Design (API RP 2A WSD); American Petroleum Institute (API): Washington, DC, USA, 2000.

5. DNV. Offshore Standard DNV-OS-J101, Design of Offshore Wind Turbine Structures; Det Norske Veritas: Høvik, Norway, 2014.

6. Augustesen, A.H.; Brødbæk, K.T.; Møller, M.; Sørensen, S.P.H.; Ibsen, L.B.; Pedersen, T.S.; Andersen, L. Numerical Modelling of Large-Diameter Steel Piles at Horns Rev. In Proceedings of the Twelfth International Conference on Civil, Structural and Environmental Engineering Computing 2009, Funchal, Madeira, Portugal, 1-4 September 2009. Paper 239.

7. Yang, M.; Ge, B.; Li, W. Force on the laterally loaded monopile in sandy soil. Eur. J. Environ. Civ. Eng. 2018. [CrossRef]

8. LeBlanc, C.; Houlsby, G.T.; Byrne, B.W. Response of stiff piles in sand to long-term cyclic lateral loading. Géotechnique 2010, 60, 79-90. [CrossRef]

9. Roesen, H.R.; Ibsen, L.B.; Andersen, L.V. Experimental testing of monopiles in sand subjected to one-way long-term cyclic lateral loading. In Proceedings of the Int. Conference on Soil Mechanics and Geotechnical Engineering (ICSMGE), Paris, France, 2-6 September 2013; pp. 2391-2394.

10. El Haffar, I. Physical Modeling and Study of the Behaviour of Deep Foundations of Offshore Wind Turbines in Sand. Ph.D. Thesis, École Centrale de Nantes, Nantes, France, 2020.

11. Puech, A.; Garnier, J. Design of Piles under Cyclic Loading, SOLCYP Recommendations; ISTE Editions: London, UK, 2017.

12. Lin, S.-S.; Liao, J.-C. Permanent strains of piles in sand due to cyclic lateral loads. J. Geotech. Geoenviron. Eng. 1999, 125, 798-802. [CrossRef]

13. Verdure, L.; Garnier, J.; Levacher, D. Lateral cyclic loading of single piles in sand. Int. J. Phys. Model. Geotech. 2003, 3, 17-28. [CrossRef]

14. Peralta, V.P. Investigations on the Behaviour of Large Diameter Piles under Long-Term Lateral Cyclic Loading in Cohesionless Soil. Ph.D. Thesis, University of Hannover, Hannover, Germany, 2010.

15. Rosquoët, F.; Thorel, L.; Garnier, J.; Canepa, Y. Lateral cyclic loading of sand installed piles. Soils Found. 2007, 47, 821-832. [CrossRef]

16. Wolf, T.K.; Rasmussen, K.L.; Hansen, M.; Roesen, H.R.; Ibsen, L.B. Assessment of p-y Curves from Numerical Methods for a Non-slender Monopile in Cohesionless Soil; Technical Memorandum No. 024; Department of Civil Engineering, Aalborg University: Aalborg, Denmark, 2013; 17p.

17. Achmus, M.; Kuo, Y.S.; Abdel-Rahman, K. Behaviour of monopile foundations under cyclic lateral load. Comput. Geotech. 2009, 36, 725-735. [CrossRef]

18. Su, D.; Li, J.H. Three-dimensional finite element study of a single pile response to multidirectional lateral loadings incorporating the simplified state-dependent dilatancy model. Comput. Geotech. 2013, 50, 129-142. [CrossRef]

19. Lovera, A.; Ghabezloo, S.; Sulem, J.; Randoplh, M.; Kham, M.; Palix, E. Pile response to multi-directional lateral loading using P-y curves approach. Géotechnique 2020. [CrossRef]

20. Mayoral, J.M.; Pestana, J.M.; Seed, R.B. Multi-directional cyclic p-y curves for soft clay. Ocean Eng. 2016, 115, 1-18. [CrossRef] 
21. Rudolph, C.; Bienen, B.; Grabe, J. Effect of variation of the loading direction on the displacement accumulation of large-diameter piles under cyclic lateral loading in sand. Can. Geotech. J. 2014, 51, 1-11. [CrossRef]

22. Itasca Consulting Group Inc. Flac3D User's Guide, v.5.01; Itasca Consulting group Inc.: Minneapolis, MN, USA, November 2013.

23. France Energies Marines. Actions R\&D sur la mutualisation des ancrages pour l'éolien flottant. Presented at CFMS Mirror Group TC 209, Marne-La-Vallée, France, 26 September 2019.

24. Obaei, A. Numerical Modelling of a New Type of Foundation System for Offshore Applications. Master's Thesis, Université Grenoble Alpes, Grenoble, France, 2020.

25. Detournay, C.; Wang, Z.; Han, Y. Modeling of Nevada Sand Behaviour Using CHSOIL. In Proceedings of the 2nd FLAC/DEM Symposium - Continuum and Distinct Element Numerical Modeling in Geomechanics, Melbourne, Australia, 14-16 February 2011; Sainsbury, D., Hart, R., Detournay, C., Nelson, M., Eds.; pp. 8-13.

26. Abadie, C.N.; Byrne, B.W.; Houlsby, G.T. Rigid pile response to cyclic lateral loading: Laboratory tests. Géotechnique 2019, 69, 863-876. [CrossRef]

27. Lesny, K.; Hinz, P. Investigation of monopile behaviour under cyclic lateral loading. In Proceedings of the 6th International Conference on Offshore Site Investigation and Geotechnics, London, UK, 26-28 November 2007; pp. 383-390.

28. Page, A.M.; Klinkvort, R.T.; Bayton, S.; Zhang, Y.; Jostad, H.P. A procedure for predicting the permanent rotation of monopiles in sand supporting offshore wind turbines. Mar. Struct. 2021, 75. [CrossRef] 